\title{
Design Of 2-D Recursive Digital Filters Using Nonsymmetric Half-Plane Allpass Filters
}

\author{
Yuan-Hau Yang and Ju-Hong Lee
}

\begin{abstract}
A novel structure using recursive nonsymmetric half-plane (NSHP) digital allpass filters (DAFs) is presented for designing 2-D recursive digital filters. First, several important properties of 2-D recursive DAFs with NSHP support regions for filter coefficients are investigated. The stability of the 2-D recursive NSHP DAFs is guaranteed by using a spectral factorization-based algorithm. Then, the important characteristics regarding the proposed novel structure are discussed. The design problem of 2-D recursive digital filters using the novel structure is considered. We formulate the problem by forming an objective function consisting of the weighted sum of magnitude, group delay, and stability-related errors. A design technique using a trust-region Newton-conjugate gradient method in conjunction with the analytic derivatives of the objective function is presented to efficiently solve the resulting optimization problem. The novelty of the presented 2-D structure is that it possesses the advantage of better performance in designing a variety of 2-D recursive digital filters over existing 2-D filter structures. Finally, several design examples are provided for conducting illustration and comparison.
\end{abstract}

Index Terms-Allpass filter, nonsymmetric half-plane (NSHP), nonlinear optimization, 2-D recursive filter.

\section{INTRODUCTION}

$\mathbf{M}$ ANY techniques have been presented for the design of 1-D recursive digital filters using the parallel combination of 1-D allpass sections [1]-[5]. The designed 1-D recursive digital filters structures possess very low passband sensitivity and doubly complementary (DC) properties. The design of 1-D DC digital filters using two complex allpass sections is considered in [2] and [3] and using two real allpass sections is discussed in [4] and [5]. One-dimensional allpass filters are further utilized to construct the analysis/synthesis filters of quadrature-mirror filter (QMF) banks. It has been shown in [3]-[5] that the designed infinite impulse response (IIR) QMF banks provide approximately linear phase response without magnitude distortion. In [14], 1-D allpass filter structures have been successfully applied to the design of two-channel nonuniform-division filter (NDF) banks.

\footnotetext{
Manuscript received April 18, 2006; revised March 26, 2007. This work was supported by the National Science Council of Taiwan, R.O.C., under Grant NSC94-2213-E002-074. The associate editor coordinating the review of this manuscript and approving it for publication was Dr. Timothy N. Davidson.

Y.-H. Yang is with the Graduate Institute of Communication Engineering, EE II - 517, National Taiwan University, Taipei 10617, Taiwan, R.O.C. (e-mail: d92942011@ ntu.edu.tw).

J.-H. Lee is with the Department of Electrical Engineering, Graduate Institute of Communication Engineering, and the Graduate Institute of Biomedical Electronics and Bioinformatics, National Taiwan University, Taipei 10617, Taiwan, R.O.C. (e-mail: juhong@cc.ee.ntu.edu.tw).

Color versions of one or more of the figures in this paper are available online at http://ieeexplore.ieee.org.

Digital Object Identifier 10.1109/TSP.2007.900172
}

Recently, the extension of the 1-D allpass structure to the design of 2-D recursive digital filters has been widely considered in the literature [6]-[9]. In [6], 2-D recursive circularly symmetric lowpass filters with quarter-plane $(\mathrm{QP})$ support region for filter coefficients are constructed by using a parallel connection of a 2-D allpass filter and an appropriate delay element in the form of $z_{1}^{-M_{1}} z_{2}^{-M_{2}}$. However, this structure induces some undesired passbands so that a noncausal system and a 1-D lowpass guard filter are required to eliminate the extra spikes and achieve the circularly symmetric characteristics. To get rid of the delay elements, a modification to the technique has been reported in [7] by utilizing a parallel connection of two allpass sections with appropriate filter orders. Nevertheless, causality and stability of the designed filters are not guaranteed by using these two techniques. Unlike [6] and [7], the techniques presented in [8] and [9] employ four allpass building blocks with appropriate delay elements to achieve arbitrary cut-off boundaries for 2-D recursive digital filters with QP coefficients. During the design process, the stability of the 2-D recursive digital filters is guaranteed by assigning a two-variable very strictly Hurwitz polynomial to the denominator of a 2-D analog allpass function and discretizing the analog function through double bilinear transformation. The main limitation of these design techniques is that none of them possesses the capabilities in designing the most general 2-D causal recursive digital filter subject to the approximation of frequency response in some optimal sense.

In this paper, a novel structure, composed of nonsymmetric half-plane (NSHP) allpass filters, for the design of 2-D recursive filters is presented. It has been shown in [10]-[13] that 2-D recursive NSHP filters outperform 2-D recursive QP filters in terms of approximating more general frequency response specification. We first develop some results of 2-D recursive NSHP digital allpass filters (DAFs). The stability of the designed 2-D recursive NSHP DAFs is guaranteed by using a penalty function involving a stability error computed by using spectral factorization-based algorithm [11]. Several important properties of the developed 2-D recursive NSHP DAFs are investigated. Then, the 2-D recursive NSHP DAFs are utilized as the fundamental building blocks to construct 2-D recursive digital filters. By selecting appropriate filter orders and parameters for the 2-D recursive NSHP DAFs, the proposed 2-D recursive NSHP digital filters possess general approximation capabilities without requiring additional delay elements for the design specifications with various cutoff boundaries. We formulate the design problem of 2-D recursive NSHP digital filters by forming an objective function consisting of the weighted sum of magnitude, group delay, and stability related errors. The derivatives of the objective function required for performing optimization are derived analytically. A technique based on a trust-region Newton-conjugate gradient method [15], [16] is presented to efficiently solve the resulting nonlinear optimization problem. 
The effectiveness of the research work is shown by several design examples.

This paper is organized as follows. Section II presents the theoretical results of 2-D recursive NSHP DAFs. The spectral factorization-based algorithm for stability is briefly reviewed. Section III presents the results of 2-D recursive NSHP filters using the 2-D recursive NSHP DAFs. In Section IV, we formulate the problem for designing 2-D recursive digital filters. A design technique based on a trust-region Newton-conjugate gradient method is presented. Section V presents several design examples for illustration and comparison. Finally, we conclude the paper in Section VI.

\section{Two-DimensionAl RECURSIVE NSHP Digital ALLPASS FILTER}

\section{A. Conventional 2-D Recursive Digital Allpass Filters (DAFs)}

For a conventional 2-D recursive DAF with order $M \times N$, its transfer function is given by

$$
A\left(z_{1}, z_{2}\right)=z_{1}^{-M} z_{2}^{-N} \frac{D\left(z_{1}^{-1}, z_{2}^{-1}\right)}{D\left(z_{1}, z_{2}\right)} .
$$

The real coefficient array $d(m, n)$ of $D\left(z_{1}, z_{2}\right)$ has the support region restricted in the first quadrant plane $(\mathrm{QP})$ of the $(m, n)$ plane. The denominator of (1) can be expressed as

$$
D\left(z_{1}, z_{2}\right)=\sum_{m=0}^{M} \sum_{n=0}^{N} d(m, n) z_{1}^{-m} z_{2}^{-n} .
$$

\section{B. Two-Dimensional Recursive NSHP DAFs}

Here, we develop a 2-D recursive DAF which possesses a more general causality than the conventional 2-D recursive DAFs. Consider a 2-D recursive DAF $A\left(z_{1}, z_{2}\right)$ with order $M \times N$ and the NSHP support region for its real coefficient array $d(m, n)$. Fig. 1 depicts the NSHP support region for $d(m, n)$ with $M=3$ and $N=2$. Accordingly, the denominator $D\left(z_{1}, z_{2}\right)$ of $A\left(z_{1}, z_{2}\right)$ is given by

$$
\begin{aligned}
D\left(z_{1}, z_{2}\right)=\sum_{m=0}^{M} d(m, 0) & z_{1}^{-m} \\
& +\sum_{m=-M}^{M} \sum_{n=1}^{N} d(m, n) z_{1}^{-m} z_{2}^{-n} .
\end{aligned}
$$

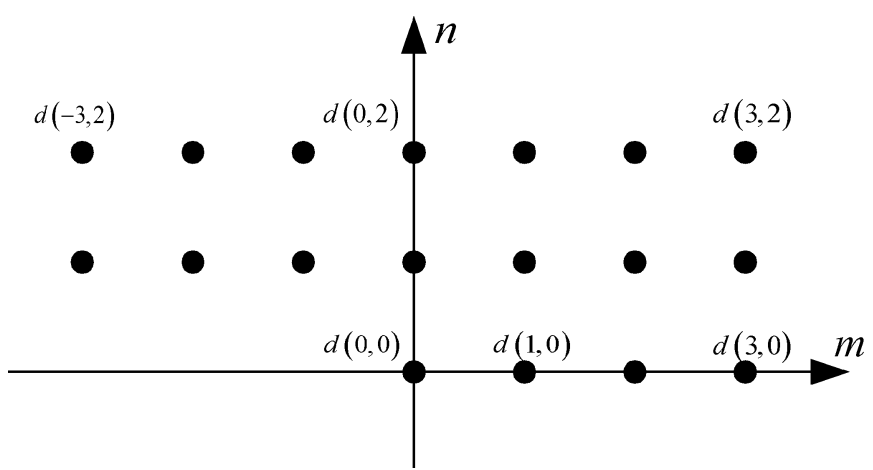

Fig. 1. NSHP support region of (3) with $M=3$ and $N=2$.

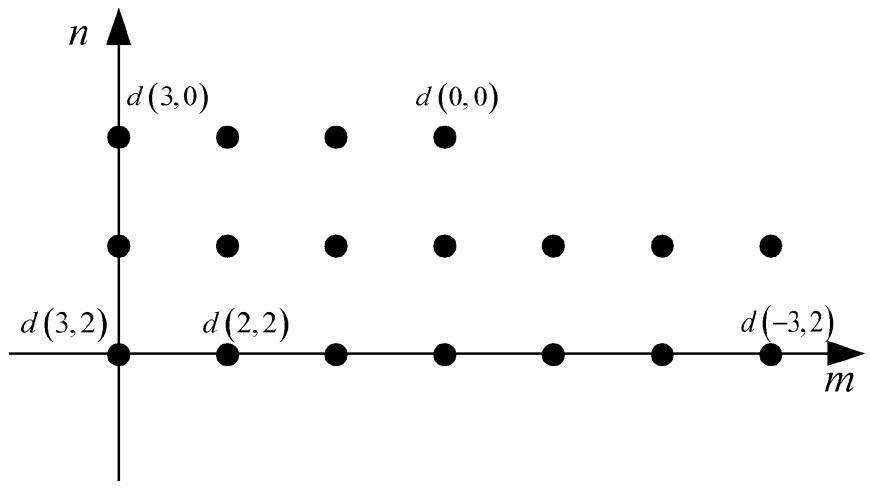

Fig. 2. Support region of $N\left(z_{1}, z_{2}\right)$ in (4) with $M=3$ and $N=2$.

Replacing the denominator of (1) with (3) gives the transfer function of a 2-D recursive NSHP DAF with order $M \times N$ as shown in (4), at the bottom of the page, where

$$
\begin{aligned}
N\left(z_{1}, z_{2}\right)=\sum_{m=0}^{M} d( & M-m, 0) z_{1}^{-m} z_{2}^{-N} \\
& +\sum_{m=0}^{2 M} \sum_{n=0}^{N-1} d(M-m, N-n) z_{1}^{-m} z_{2}^{-n}
\end{aligned}
$$

denotes the numerator of the 2-D recursive NSHP DAF and has the support region shown by Fig. 2 for its coefficients. Considering the frequency points (termed as the crucial points in [8] and [9]) in the $\left(\omega_{1}, \omega_{2}\right)$ plane, as shown by the open circles in Fig. 3, we investigate the frequency characteristics of the 2-D recursive DAF and present two important properties as follows, where $\Omega_{\mathrm{CP}}$ denotes the set of the crucial points (CPs).

1) Property 1: The phase response $\phi\left(\omega_{1}, \omega_{2}\right)=$ $\arg \left\{D\left(e^{j \omega_{1}}, e^{j \omega_{2}}\right)\right\}$ of $D\left(e^{j \omega_{1}}, e^{j \omega_{2}}\right)$ is equal to zero

$$
\begin{aligned}
A\left(z_{1}, z_{2}\right) & =\frac{\sum_{m=0}^{M} d(M-m, 0) z_{1}^{-m} z_{2}^{-N}+\sum_{m=0}^{2 M} \sum_{n=0}^{N-1} d(M-m, N-n) z_{1}^{-m} z_{2}^{-n}}{\sum_{m=0}^{M} d(m, 0) z_{1}^{-m}+\sum_{m=-M}^{M} \sum_{n=1}^{N} d(m, n) z_{1}^{-m} z_{2}^{-n}} \\
& =\frac{N\left(z_{1}, z_{2}\right)}{D\left(z_{1}, z_{2}\right)}
\end{aligned}
$$




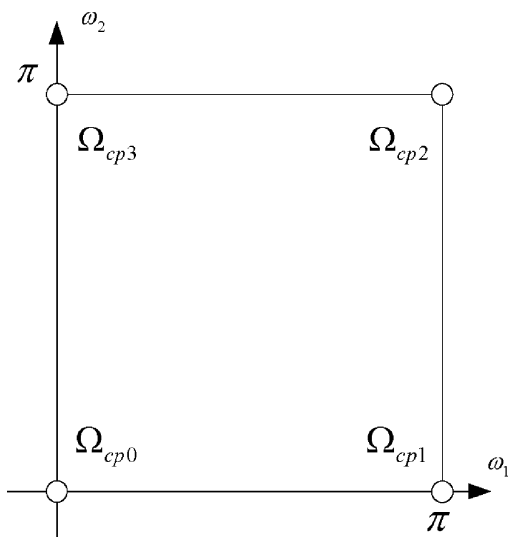

Fig. 3. Crucial points (indicated by the open circles) in the $\left(\omega_{1}, \omega_{2}\right)$ plane.

TABLE I

FREQUENCY RESPONSE OF A 2-D IIR ALLPASS FILTER AT THE CPS

\begin{tabular}{|c|c|c|}
\hline $\begin{array}{c}\text { Crucial } \\
\text { Points }\end{array}$ & Order of $A\left(\omega_{1}, \omega_{2}\right)$ & $A\left(\omega_{1}, \omega_{2}\right)$ \\
\hline$\Omega_{c p 0}$ & For all $M$ and $N$ & 1 \\
\hline \multirow{2}{*}{$\Omega_{c p 1}$} & $M$ odd & -1 \\
\cline { 2 - 3 } & $M$ even & 1 \\
\hline \multirow{2}{*}{$\Omega_{c p 2}$} & $M+N$ odd & -1 \\
\cline { 2 - 3 } & $M+N$ even & 1 \\
\hline \multirow{2}{*}{$\Omega_{c p 3}$} & $N$ odd & -1 \\
\cline { 2 - 3 } & $N$ even & 1 \\
\hline
\end{tabular}

at the CPs. As a result, the phase response $\theta\left(\omega_{1}, \omega_{2}\right)=$ $\arg \left\{A\left(e^{j \omega_{1}}, e^{j \omega_{2}}\right)\right\}$ of $A\left(e^{j \omega_{1}}, e^{j \omega_{2}}\right)$ is given by

$$
\begin{aligned}
\left.\theta\left(\omega_{1}, \omega_{2}\right)\right|_{\left(\omega_{1}, \omega_{2}\right) \in \Omega_{C P}} & =\arg \left\{\left.A\left(e^{j \omega_{1}}, e^{j \omega_{2}}\right)\right|_{\left(\omega_{1}, \omega_{2}\right) \in \Omega_{C P}}\right\} \\
& =-M \omega_{1}-N \omega_{2} .
\end{aligned}
$$

2) Property 2: The frequency responses of the 2-D recursive DAF $A\left(e^{j \omega_{1}}, e^{j \omega_{2}}\right)$ are restricted to be 1 or -1 at the CPs. The details of this property are listed in Table I.

Therefore, the values of $M$ and $N$ for the orders of the 2-D recursive DAF must be appropriately specified to avoid possible unwanted passbands or stopbands.

\section{Stability of 2-D Recursive NSHP DAFs}

To ensure the stability of a 2-D recursive NSHP DAF during the design process, the spectral factorization-based algorithm of [11] and [12] that constrains stability by use of a penalty function involving a stability error computed using the cepstral stability test of [10] is utilized. We briefly review the 2-D stabilization scheme based on the spectral factorization-based algorithm.

Consider a 2-D transfer function $R\left(z_{1}, z_{2}\right)$ with two spectral factors shown as follows:

$$
R\left(z_{1}, z_{2}\right)=R_{+}\left(z_{1}, z_{2}\right) R_{-}\left(z_{1}^{-1}, z_{2}^{-1}\right)
$$

where $R_{+}\left(z_{1}, z_{2}\right)$ denotes the causal spectral factor with a coefficient array $r_{+}(m, n)$ of an NSHP support region $\mathfrak{R}_{+}$and $R_{-}\left(z_{1}^{-1}, z_{2}^{-1}\right)$ the anti-causal spectral factor with a coefficient

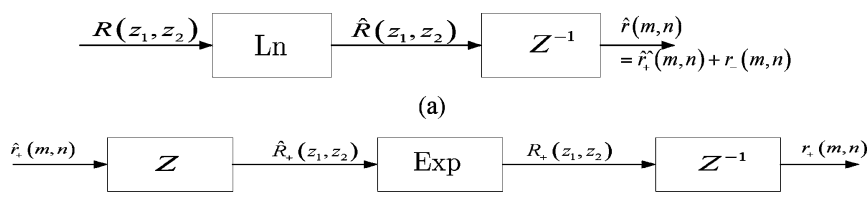

(b)

Fig. 4. Systems of the (a) homomorphic transform and (b) inverse homomorphic transform.

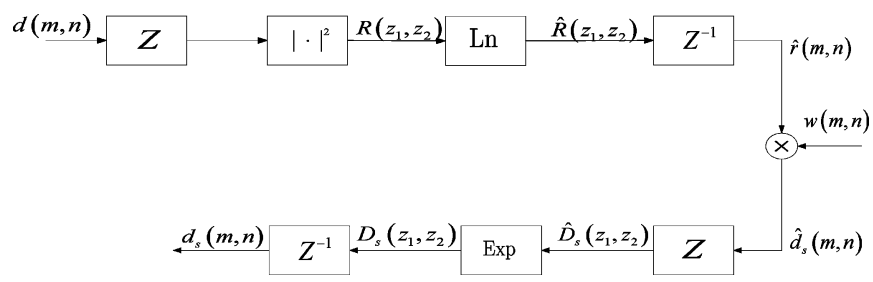

Fig. 5. Two-dimensional spectral factorization with NSHP window function $w(m, n)$

array $r_{-}(m, n)$ of an NSHP support region $\mathfrak{R}_{-}$. These NSHP spectral factors can be obtained by using the 2-D spectral factorization approach as shown by Fig. 4 . The approach performs an NSHP projection to a factorization involving the region of homomorphy for (6) as

$$
\begin{aligned}
& R_{+}\left(z_{1}, z_{2}\right) \neq 0, \text { for }\left(z_{1}, z_{2}\right) \in\left\{\left|z_{1}\right|=1,\left|z_{2}\right| \geqq 1\right\} \\
& R_{+}\left(z_{1}, \infty\right) \neq 0, \text { for } z_{1} \in\left\{\left|z_{1}\right| \geqq 1\right\}
\end{aligned}
$$

and

$$
\begin{aligned}
& R_{-}\left(z_{1}, z_{2}\right) \neq 0, \text { for }\left(z_{1}, z_{2}\right) \in\left\{\left|z_{1}\right|=1,\left|z_{2}\right| \leqq 1\right\} \\
& R_{-}\left(z_{1}, \infty\right) \neq 0, \text { for } z_{1} \in\left\{\left|z_{1}\right| \leqq 1\right\} .
\end{aligned}
$$

As a result, the coefficient array $r(m, n)$ is decomposed into two factors as follows:

$$
r(m, n)=r_{+}(m, n) * r_{-}(m, n)
$$

where "*" denotes 2-D convolution operation. Moreover, the factor $r_{+}(m, n)$ with support on $\mathfrak{R}_{+}$possesses two analytical properties: i) $r_{+}(m, n)$ is mix-min phase due to (7) and ii) $r_{+}(m, 0)$ is 1-D min phase due to (8).

We apply the above theoretical result to stabilize the 2-D recursive NSHP DAF with transfer function given by (4). Fig. 5 shows a spectral factorization of the filter denominator's square magnitude, where $d(m, n)$ denotes the denominator's coefficient array of (4) and $d_{s}(m, n)$ is the causal spectral factor of $\left|D\left(e^{j \omega_{1}}, e^{j \omega_{2}}\right)\right|^{2}$. The window function $w(m, n)$ in Fig. 5 is employed to truncate and smooth the generally infinite-dimensional coefficient array $\hat{r}(m, n)$ to obtain a finite-order approximation $\hat{d}_{s}(m, n)$. We adopt the simplest one for performing simulation examples: $w(m, n)=1$ for $n>0$, and for $n=0$, $m>0, w(0,0)=1 / 2$, and $w(m, n)=0$, elsewhere. The truncation-type windowing provides a direct manner of generating a finite-order factor $d_{s}(m, n)$. The stability of the truncated factor $d_{s}(m, n)$ should be considered during the design process. A stability error is given by

$$
\varepsilon_{s}(m, n)=d(m, n)-d_{s}(m, n) .
$$




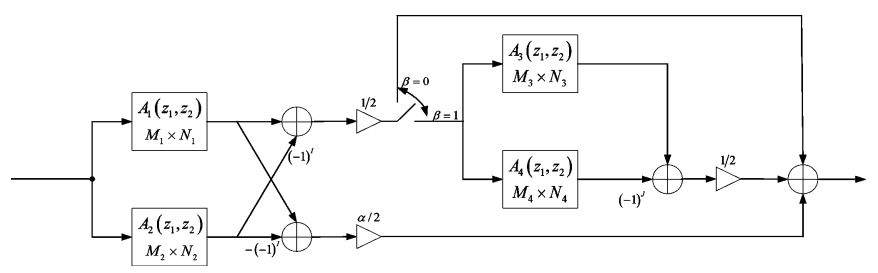

Fig. 6. Block diagram of the proposed structure (13).

According to the 2-D spectral factorization approach illustrated in Fig. 5, if the denominator coefficients $d(m, n)$ of a 2-D recursive filter are stable minimum-phase coefficients, the $d(m, n)$ equals the coefficient $d_{s}(m, n)$ for each $(m, n)$. Otherwise, there exists a difference between $d(m, n)$ and $d_{s}(m, n)$. Therefore, to obtain a stable design, the difference between $d(m, n)$ and $d_{s}(m, n)$ (termed as stability error) can be utilized as a constraint or a penalty function to penalize the deviation of $d(m, n)$ from $d_{s}(m, n)$ during the design process.

\section{Two-Dimensional Recursive FILTER Structure USING 2-D NSHP DAFS}

Here, we develop the results for the structure of a 2-D recursive digital filter using the 2-D recursive NSHP DAFs presented in Section II. We also demonstrate its applications in designing several widely used 2-D digital filters.

\section{A. Proposed 2-D Recursive Filter Structure Using 2-D NSHP DAFs}

Using the 2-D recursive NSHP DAF, we construct a 2-D recursive digital filter $H\left(z_{1}, z_{2}\right)$ of Fig. 6 as follows:

$$
\begin{aligned}
H\left(z_{1}, z_{2}\right)= & \left\{\frac{1}{2}\left[A_{1}\left(z_{1}, z_{2}\right)+(-1)^{I} A_{2}\left(z_{1}, z_{2}\right)\right]\right\} \\
& \cdot\left\{\frac{1}{2}\left[A_{3}\left(z_{1}, z_{2}\right)+(-1)^{J} A_{4}\left(z_{1}, z_{2}\right)\right]\right\}^{\beta} \\
& +\frac{\alpha}{2}\left[A_{1}\left(z_{1}, z_{2}\right)-(-1)^{I} A_{2}\left(z_{1}, z_{2}\right)\right]
\end{aligned}
$$

where $A_{i}\left(z_{1}, z_{2}\right)$ is the 2-D recursive NSHP DAF with order $M_{i} \times N_{i}$ and transfer function given by (4) for $i=1,2,3,4$. The values of $\alpha, \beta, I$, and $J$ are set to 0 or 1 according to the filter design specifications. From (13), we consider two filter subsections as follows:

$$
S_{+}\left(z_{1}, z_{2}\right)=\frac{1}{2}\left[A_{i}\left(z_{1}, z_{2}\right)+A_{i+1}\left(z_{1}, z_{2}\right)\right], \text { for } i=1,3
$$

and

$$
S_{-}\left(z_{1}, z_{2}\right)=\frac{1}{2}\left[A_{i}\left(z_{1}, z_{2}\right)-A_{i+1}\left(z_{1}, z_{2}\right)\right] \text {, for } i=1,3 .
$$

It has been shown in [1] that the structure of two parallel-connected 1-D DAFs provides very low passband sensitivity. Moreover, its superior roundoff noise performance could make shorter coefficient wordlengths possible. It would be expected that the structures of (14) and (15) also enjoy these favorable properties.

Let the frequency response of the 2-D recursive NSHP DAF of (4) be expressed by

$$
A\left(e^{j \omega_{1}}, e^{j \omega_{2}}\right)=e^{j \theta\left(\omega_{1}, \omega_{2}\right)}
$$

where the phase $\theta\left(\omega_{1}, \omega_{2}\right)$ is given by

$$
\begin{aligned}
\theta\left(\omega_{1}, \omega_{2}\right) & =\arg \left[A\left(e^{j \omega_{1}}, e^{j \omega_{2}}\right)\right] \\
& =-M \omega_{1}-N \omega_{2}-2 \phi\left(\omega_{1}, \omega_{2}\right)
\end{aligned}
$$

and $\phi\left(\omega_{1}, \omega_{2}\right)=\arg \left[D\left(e^{j \omega_{1}}, e^{j \omega_{2}}\right)\right]$. Substituting (16) into (14) yields

$$
\begin{aligned}
S_{+} & \left(e^{j \omega_{1}}, e^{j \omega_{2}}\right) \\
= & \frac{1}{2}\left[A_{i}\left(e^{j \omega_{1}}, e^{j \omega_{2}}\right)+A_{i+1}\left(e^{j \omega_{1}}, e^{j \omega_{2}}\right)\right] \\
= & \frac{1}{2}\left[e^{j \theta_{i}\left(\omega_{1}, \omega_{2}\right)}+e^{j \theta_{i+1}\left(\omega_{1}, \omega_{2}\right)}\right] \\
= & \cos \left\{\frac{\left[\theta_{i}\left(\omega_{1}, \omega_{2}\right)-\theta_{i+1}\left(\omega_{1}, \omega_{2}\right)\right]}{2}\right\} \\
& \times e^{j\left[\theta_{i}\left(\omega_{1}, \omega_{2}\right)+\theta_{i+1}\left(\omega_{1}, \omega_{2}\right)\right] / 2} .
\end{aligned}
$$

Substituting (17) into (18) yields (19), shown at the bottom of the page. As shown in Property 1 of Section II, the phase functions have the values $\phi_{i}\left(\omega_{1}, \omega_{2}\right)=0$ and $\phi_{i+1}\left(\omega_{1}, \omega_{2}\right)=0$ for $\left(\omega_{1}, \omega_{2}\right) \in \Omega_{C P}$. Hence, the frequency response $S_{+}\left(e^{j \omega_{1}}, e^{j \omega_{2}}\right)$ becomes

$$
\begin{aligned}
S_{+} & \left(e^{j \omega_{1}}, e^{j \omega_{2}}\right) \mid\left(\omega_{1}, \omega_{2}\right) \in \Omega_{C P} \\
= & \cos \left(-\frac{M_{i}-M_{i+1}}{2} \omega_{1}-\frac{N_{i}-N_{i+1}}{2} \omega_{2}\right) \\
& \times \exp \left\{j\left(-\frac{M_{i}+M_{i+1}}{2} \omega_{1}-\frac{N_{i}+N_{i+1}}{2} \omega_{2}\right)\right\}
\end{aligned}
$$

$$
\begin{aligned}
S_{+}\left(e^{j \omega_{1}}, e^{j \omega_{2}}\right)= & \cos \left[-\frac{M_{i}-M_{i+1}}{2} \omega_{1}-\frac{N_{i}-N_{i+1}}{2} \omega_{2}-\phi_{i}\left(\omega_{1}, \omega_{2}\right)+\phi_{i+1}\left(\omega_{1}, \omega_{2}\right)\right] \\
& \times \exp \left\{j\left[-\frac{M_{i}+M_{i+1}}{2} \omega_{1}-\frac{N_{i}+N_{i+1}}{2} \omega_{2}-\phi_{i}\left(\omega_{1}, \omega_{2}\right)-\phi_{i+1}\left(\omega_{1}, \omega_{2}\right)\right]\right\}
\end{aligned}
$$


TABLE II

RELATIONSHIP BETWEEN $\left|S_{+}\left(e^{j \omega_{1}}, e^{j \omega_{2}}\right)\right|$ FOR $\left(\omega_{1}, \omega_{2}\right) \in \Omega_{C P}$ AND THE ORDERS OF ALLPASS FILTERS

\begin{tabular}{|c|c|c|}
\hline & $\left.\mid \omega_{1}, \omega_{2}\right)$ & $\left|S_{+}\left(e^{j \omega_{1}}, e^{j \omega_{2}}\right)\right|=1$ \\
\hline$\Omega_{c p 0}$ & $\left.\begin{array}{c}\text { for all } M_{i}-M_{i+1} \\
\text { and } N_{i}-N_{i+1}\end{array}\right)=0$ \\
\hline$\Omega_{c p 1}$ & $M_{i}-M_{i+1}$ even & Impracticable \\
\hline \multirow{2}{*}{$\Omega_{c p 2}$} & $M_{i}-M_{i+1}$ even, $N_{i}-N_{i+1}$ even & $M_{i}-M_{i+1}$ odd \\
\cline { 2 - 3 } & $M_{i}-M_{i+1}$ odd, $N_{i}-N_{i+1}$ odd & $M_{i}-M_{i+1}$ odd, $N_{i}-N_{i+1}$ odd \\
\hline$\Omega_{c p 3}$ & $N_{i}-N_{i+1}$ even & $N_{i}-N_{i+1}$ odd \\
\hline
\end{tabular}

TABLE III

RELATIONSHIP BETWEEN $\left|S_{-}\left(e^{j \omega_{1}}, e^{j \omega_{2}}\right)\right|$ FOR $\left(\omega_{1}, \omega_{2}\right) \in \Omega_{C P}$ AND THE ORDERS OF ALLPASS Filters

\begin{tabular}{|c|c|c|}
\hline$\left(\omega_{1}, \omega_{2}\right)$ & $\left|S_{-}\left(e^{j \omega_{1}}, e^{j \omega_{2}}\right)\right|=1$ & $\left|S_{-}\left(e^{j \omega_{1}}, e^{j \omega_{2}}\right)\right|=0$ \\
\hline$\Omega_{c p 0}$ & Impracticable & $\begin{array}{c}\text { for all } M_{i}-M_{i+1} \\
\text { and } N_{i}-N_{i+1}\end{array}$ \\
\hline$\Omega_{c p 1}$ & $M_{i}-M_{i+1}$ odd & $M_{i}-M_{i+1}$ even \\
\hline \multirow{2}{*}{$\Omega_{c p 2}$} & $M_{i}-M_{i+1}$ even, $N_{i}-N_{i+1}$ odd & $M_{i}-M_{i+1}$ even, $N_{i}-N_{i+1}$ even \\
\cline { 2 - 3 } & $M_{i}-M_{i+1}$ odd, $N_{i}-N_{i+1}$ even & $M_{i}-M_{i+1}$ odd, $N_{i}-N_{i+1}$ odd \\
\hline$\Omega_{c p 3}$ & $N_{i}-N_{i+1}$ odd & $N_{i}-N_{i+1}$ even \\
\hline
\end{tabular}

for $\left(\omega_{1}, \omega_{2}\right) \in \Omega_{C P}$. Equation (20) shows that the frequency response $\left.S_{+}\left(e^{j \omega_{1}}, e^{j \omega_{2}}\right)\right|_{\left(\omega_{1}, \omega_{2}\right) \in \Omega_{C P}}$ is only a function of $M_{i}$, $M_{i+1}, N_{i}$, and $N_{i+1}$. Therefore, the orders $M_{i} \times N_{i}$ and $M_{i+1} \times$ $N_{i+1}$ of $A_{i}\left(e^{j \omega_{1}}, e^{j \omega_{2}}\right)$ and $A_{i+1}\left(e^{j \omega_{1}}, e^{j \omega_{2}}\right)$ should be appropriately chosen to approximate the desired filter specifications. The details regarding the relationship between $\left|S_{+}\left(e^{j \omega_{1}}, e^{j \omega_{2}}\right)\right|$ for $\left(\omega_{1}, \omega_{2}\right) \Omega_{C P}$ and the orders $M_{i} \times N_{i}, M_{i+1} \times N_{i+1}$ are listed in Table II. Similarly, the frequency response of (15) is given as follows:

$$
\begin{aligned}
S_{-} & \left(e^{j \omega_{1}}, e^{j \omega_{2}}\right) \\
= & \frac{1}{2}\left[A_{i}\left(e^{j \omega_{1}}, e^{j \omega_{2}}\right)-A_{i+1}\left(e^{j \omega_{1}}, e^{j \omega_{2}}\right)\right] \\
= & \frac{1}{2}\left[e^{j \theta_{i}\left(\omega_{1}, \omega_{2}\right)}-e^{j \theta_{i+1}\left(\omega_{1}, \omega_{2}\right)}\right] \\
= & \sin \left\{\frac{\left[\theta_{i}\left(\omega_{1}, \omega_{2}\right)-\theta_{i+1}\left(\omega_{1}, \omega_{2}\right)\right]}{2}\right\} \\
& \left.\cdot e^{j\left[\theta_{i}\left(\omega_{1}, \omega_{2}\right)+\theta_{i+1}\left(\omega_{1}, \omega_{2}\right)+\pi\right] / 2}\right\} \\
= & \sin \left[-\frac{M_{i}-M_{i+1}}{2} \omega_{1}-\frac{N_{i}-N_{i+1}}{2} \omega_{2}\right. \\
& \left.-\phi_{i}\left(\omega_{1}, \omega_{2}\right)+\phi_{i+1}\left(\omega_{1}, \omega_{2}\right)\right] \\
& \times \exp \left\{j \left[-\frac{M_{i}+M_{i+1}}{2} \omega_{1}-\frac{N_{i}+N_{i+1}}{2} \omega_{2}\right.\right. \\
& \left.\left.-\phi_{i}\left(\omega_{1}, \omega_{2}\right)-\phi_{i+1}\left(\omega_{1}, \omega_{2}\right)+\frac{\pi}{2}\right]\right\} .
\end{aligned}
$$

According to Property 1, $S_{-}\left(e^{j \omega_{1}}, e^{j \omega_{2}}\right)$ becomes

$$
\begin{aligned}
S_{-} & \left.\left(e^{j \omega_{1}}, e^{j \omega_{2}}\right)\right|_{\left(\omega_{1}, \omega_{2}\right) \in \Omega_{C P}} \\
= & \sin \left(-\frac{M_{i}-M_{i+1}}{2} \omega_{1}-\frac{N_{i}-N_{i+1}}{2} \omega_{2}\right) \\
& \times \exp \left\{j\left(-\frac{M_{i}+M_{i+1}}{2} \omega_{1}-\frac{N_{i}+N_{i+1}}{2} \omega_{2}+\frac{\pi}{2}\right)\right\} .
\end{aligned}
$$

Again, (22) shows that the frequency response $\left.S_{-}\left(e^{j \omega_{1}}, e^{j \omega_{2}}\right)\right|_{\left(\omega_{1}, \omega_{2}\right) \in \Omega_{C P}}$ is only a function of $M_{i}$, $M_{i+1}, N_{i}$, and $N_{i+1}$. Table III lists the relationship between $\left|S_{-}\left(e^{j \omega_{1}}, e^{j \omega_{2}}\right)\right|$ for $\left(\omega_{1}, \omega_{2}\right) \in \Omega_{C P}$ and the orders $M_{i} \times N_{i}, M_{i+1} \times N_{i+1}$. Table IV summarizes the frequency characteristics of the 2-D recursive filter structure shown by (13). The transfer function of (13) does not involve the filter subsections $\left[A_{3}\left(z_{1}, z_{2}\right) \pm A_{4}\left(z_{1}, z_{2}\right)\right] / 2$ for the cases with $\beta=0$. We do not have to consider the values for $J, M_{3} \times N_{3}$, and $M_{4} \times N_{4}$ as denoted by "X" in Table IV.

\section{B. Application Examples of Proposed Structure}

1) Fan Filters: The fan filters are widely used in geophysical and seismic signal processing due to their ability to discriminate certain directional information in 2-D signals [17]. Recently, 
TABLE IV

PARAMETERS OF (13) FOR VARIOUS SPECIFICATIONS

\begin{tabular}{|c|c|c|c|c|c|c|c|c|}
\hline $\begin{array}{l}\text { Parameters } \\
\text { of (13) }\end{array}$ & $\alpha$ & $I$ & $\begin{array}{l}\text { remainder of } \\
\left|M_{1}-M_{2}\right| / 2\end{array}$ & $\begin{array}{l}\text { remainder of } \\
\left|N_{1}-N_{2}\right| / 2\end{array}$ & $\beta$ & $J$ & $\begin{array}{l}\text { remainder of } \\
\left|M_{3}-M_{4}\right| / 2\end{array}$ & $\begin{array}{l}\text { remainder of } \\
\left|N_{3}-N_{4}\right| / 2\end{array}$ \\
\hline None & $\overline{0}$ & 1 & 0 & 0 & 0 & $\bar{X}$ & $\mathrm{X}$ & $\mathrm{X}$ \\
\hline All & 0 & 0 & 0 & 0 & 0 & $\mathrm{X}$ & $\mathrm{X}$ & $\mathrm{X}$ \\
\hline 0,1 & 0 & 0 & 0 & 1 & 0 & $\mathrm{X}$ & $X$ & $X$ \\
\hline 0,2 & 0 & 0 & 1 & 1 & 0 & $\mathrm{X}$ & $\mathrm{X}$ & $X$ \\
\hline 0,3 & 0 & 0 & 1 & 0 & 0 & $\mathrm{X}$ & $X$ & $X$ \\
\hline 1,2 & 0 & 1 & 1 & 0 & 0 & $\mathrm{X}$ & $X$ & $X$ \\
\hline 1,3 & 0 & 1 & 1 & 1 & 0 & $\mathrm{X}$ & $X$ & $X$ \\
\hline 2,3 & 0 & 1 & 0 & 1 & 0 & $\mathrm{X}$ & $X$ & $X$ \\
\hline \multirow{2}{*}{0} & 0 & 0 & 0 & 1 & 1 & 0 & 1 & $0 / 1$ \\
\hline & 0 & 0 & 1 & 1 & 1 & 0 & 1 & 0 \\
\hline \multirow{2}{*}{1} & 0 & 0 & 0 & 1 & 1 & 1 & 1 & $0 / 1$ \\
\hline & 0 & 1 & 1 & 0 & 1 & 1 & 1 & 1 \\
\hline \multirow{3}{*}{2} & 0 & 0 & 1 & 1 & 1 & 1 & 1 & 0 \\
\hline & 0 & 0 & 1 & 1 & 1 & 1 & 0 & 1 \\
\hline & 0 & 1 & 1 & 0 & 1 & 1 & 0 & 1 \\
\hline \multirow{2}{*}{3} & 0 & 0 & 1 & 0 & 1 & 1 & $0 / 1$ & 1 \\
\hline & 0 & 1 & 1 & 1 & 1 & 1 & 0 & 1 \\
\hline \multirow{4}{*}{$1,2,3$} & \multirow{4}{*}{1} & \multirow{4}{*}{0} & 0 & 1 & \multirow{4}{*}{1} & \multirow{4}{*}{1} & 1 & $0 / 1$ \\
\hline & & & 1 & 1 & & & 1 & 0 \\
\hline & & & & & & & 0 & 1 \\
\hline & & & 1 & 0 & & & $0 / 1$ & 1 \\
\hline \multirow{5}{*}{$0,2,3$} & 1 & 0 & 0 & 1 & 1 & 0 & 1 & $0 / 1$ \\
\hline & \multirow{2}{*}{1} & \multirow{4}{*}{1} & \multirow{2}{*}{1} & \multirow{2}{*}{0} & \multirow{2}{*}{1} & 0 & 1 & 1 \\
\hline & & & & & & 1 & 0 & 1 \\
\hline & \multirow{2}{*}{1} & & \multirow{2}{*}{1} & \multirow{2}{*}{1} & \multirow{2}{*}{1} & 0 & 1 & 0 \\
\hline & & & & & & 1 & 0 & 1 \\
\hline \multirow{6}{*}{$0,1,3$} & \multirow{2}{*}{1} & \multirow{2}{*}{0} & \multirow{2}{*}{1} & \multirow{2}{*}{1} & \multirow{2}{*}{1} & \multirow{2}{*}{0} & 0 & 1 \\
\hline & & & & & & & 1 & 0 \\
\hline & 1 & & 1 & 0 & 1 & 0 & 0 & 1 \\
\hline & & 1 & & & 1 & 1 & 1 & 1 \\
\hline & 1 & & 0 & 1 & 1 & 0 & 1 & 0 \\
\hline & & & & & & 1 & 1 & 1 \\
\hline & 1 & 0 & 1 & 0 & 1 & 0 & $0 / 1$ & 1 \\
\hline & 1 & & 1 & 1 & 1 & 0 & 0 & 1 \\
\hline $0,1,2$ & & 1 & & & & 1 & 1 & 0 \\
\hline & 1 & & 0 & 1 & 1 & 0 & 1 & 1 \\
\hline & & & & & & 1 & 1 & 0 \\
\hline
\end{tabular}

they have been employed for broadband beamforming in array signal processing [18]-[22] because an ideal fan filter with its wedged-shape frequency response is a kind of broadband beamformer. $\pm \theta$ Fan Filters: The ideal magnitude response of a $\pm \theta$ fan filter is given by

$$
\left|H_{d}\left(\omega_{1}, \omega_{2}\right)\right|= \begin{cases}1, & \text { for }\left|\omega_{2}\right|<g\left|\omega_{1}\right| \\ 0, & \text { otherwise }\end{cases}
$$




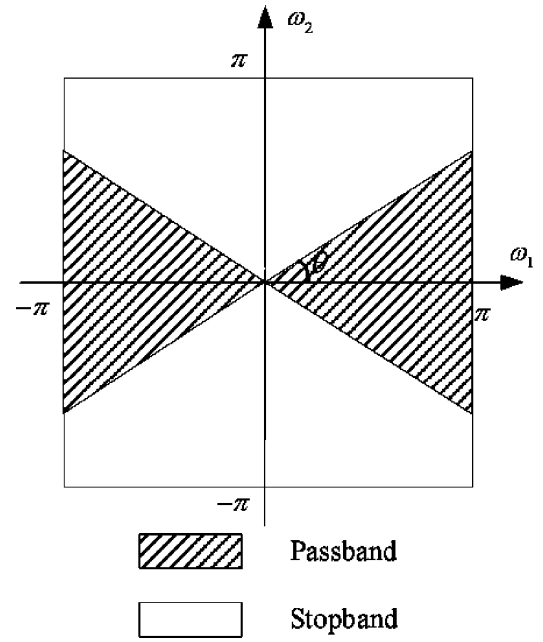

Fig. 7. Specification of the $\pm \theta$ fan filter.

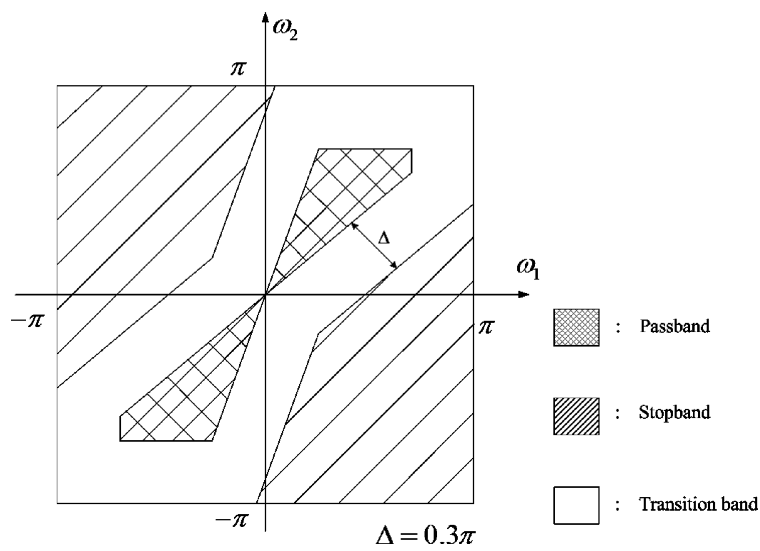

Fig. 8. Specification of the $30^{\circ}$ fan filter $\left(40^{\circ}-70^{\circ}\right)$.

where $g=\tan (\theta)$. Fig. 7 shows the ideal specification where $\Omega_{c p 0}$ and $\Omega_{c p 1}$ are included in the passband if $\theta$ is smaller than $45^{\circ}$. The value $\left|H\left(e^{j \omega_{1}}, e^{j \omega_{2}}\right)\right|$ of (13) equals 1 for $\left(\omega_{1}, \omega_{2}\right) \in$ $\Omega_{c p 0}$ and $\left(\omega_{1}, \omega_{2}\right) \in \Omega_{c p 1}$. According to Table IV, the values of $\alpha, \beta$, and $I$ of (13) must be set to 0 . Hence, the appropriate filter structure required for the $\pm \theta$ fan filter has the transfer function $H\left(z_{1}, z_{2}\right)$ given by

$$
H\left(z_{1}, z_{2}\right)=\frac{1}{2}\left[A_{1}\left(z_{1}, z_{2}\right)+A_{2}\left(z_{1}, z_{2}\right)\right]
$$

where $A_{1}\left(z_{1}, z_{2}\right)$ and $A_{2}\left(z_{1}, z_{2}\right)$ are 2-D recursive NSHP DAFs with orders $M_{1} \times N_{1}$ and $M_{2} \times N_{2}$, respectively. Moreover, the integers $\left(M_{1}-M_{2}\right) / 2$ and $\left(N_{1}-N_{2}\right) / 2$ must be even and odd, respectively.

$30^{\circ}$ Fan Filters: Fig. 8 depicts the magnitude specification for a $30^{\circ}$ fan filter with passband extending from $40^{\circ}$ to $70^{\circ}$. For applications, it can overcome a limitation of the $\pm 45^{\circ}$ fan filter because the $\pm 45^{\circ}$ fan filter cannot discriminate based on velocity but only on speed, and, hence, one cannot distinguish two waves arriving at the array from opposite directions by using a fan filter. In contrast, the $30^{\circ}$ filter would be appropriate for passing plane-wave signals arriving from one side of the array while attenuating these signals outside this angular (velocity) passband.

Due to the periodic nature of the frequency response of 2-D discrete-time systems, the added transition bands are necessary near the Nyquist frequency edges of the unit cell. From Fig. 8, we note that only $\Omega_{c p 0}$ is included in the passband of the desired magnitude response. Therefore, the magnitude response of (13) is equal to 1 for $\left(\omega_{1}, \omega_{2}\right) \in \Omega_{c p 0}$ only. From Table IV, we note that the filter structure appropriate for the $30^{\circ}$ fan filter has the transfer function given as follows:

$$
\begin{aligned}
& H\left(z_{1}, z_{2}\right)=\frac{1}{4}\left[A_{1}\left(z_{1}, z_{2}\right)+\right.\left.A_{2}\left(z_{1}, z_{2}\right)\right] \\
& \cdot\left[A_{3}\left(z_{1}, z_{2}\right)+A_{4}\left(z_{1}, z_{2}\right)\right]
\end{aligned}
$$

where $A_{i}\left(z_{1}, z_{2}\right), i=1,2,3,4$, are transfer functions of the required 2-D recursive NSHP DAFs with the orders $M_{i} \times N_{i}$ listed in the corresponding row in Table IV. From (19), it is noted that (25) is the product of two responses shown by (19). If the design specifications include the constant group delay response for the $30^{\circ}$ fan filters, such as Example 2 presented in Section V, the ideal group delays along the $\omega_{1}$ and $\omega_{2}$ axes, respectively, are given by

$$
g_{d_{1}}=\frac{\left(M_{1}+M_{2}+M_{3}+M_{4}\right)}{2}
$$

and

$$
g_{d_{2}}=\frac{\left(N_{1}+N_{2}+N_{3}+N_{4}\right)}{2} .
$$

2) Circularly Symmetric Lowpass Filters: The ideal frequency response of a circularly symmetric lowpass filter can be characterized by

$$
H_{d}\left(\omega_{1}, \omega_{2}\right)= \begin{cases}e^{-j\left(g_{d_{1}} \omega_{1}+g_{d_{2}} \omega_{2}\right)}, & \text { for } \sqrt{\omega_{1}^{2}+\omega_{2}^{2}} \leq \omega_{p} \\ 0, & \text { for } \sqrt{\omega_{1}^{2}+\omega_{2}^{2}} \geq \omega_{s}\end{cases}
$$

where the passband and stopband edges are $\omega_{p}$ and $\omega_{s}$, respectively. Moreover, $g_{d_{1}}$ and $g_{d_{2}}$ are given by (26) and (27). Equation (28) shows that only $\Omega_{c p 0}$ is included in the passband region. The filter structure $H\left(z_{1}, z_{2}\right)$ shown by (25) is also appropriate to meet the desired low-pass characteristics.

3) Diamond-Shaped Lowpass Filters: The ideal frequency response of a diamond-shaped lowpass filter is given by

$$
H_{d}\left(\omega_{1}, \omega_{2}\right)=\left\{\begin{array}{ll}
e^{-j\left(g_{d_{1}} \omega_{1}+g_{d_{2}} \omega_{2}\right)}, & \text { for }\left|\omega_{1}\right|+\left|\omega_{2}\right| \leq \omega_{p} \\
0, & \text { for }\left|\omega_{1}\right|+\left|\omega_{2}\right| \geq \omega_{s}
\end{array} .\right.
$$

It is widely used for processing image and video signals. From the above discussions regarding 2-D recursive lowpass filters, we note that the transfer function of (25) is suitable for the diamond-shaped lowpass filters since it is general for all kinds of 2-D recursive lowpass filters and not tied to any symmetric assumptions on the ideal magnitude function. 


\section{DESIGN TEChNIQUE}

\section{A. Formulation of the Design Problem}

The magnitude error between the magnitude response of (13) and the ideal magnitude response $\left|H_{d}\left(\omega_{1}, \omega_{2}\right)\right|$ is given by

$$
\begin{aligned}
& \varepsilon_{m}\left(\omega_{1}, \omega_{2}\right) \\
& \quad \triangleq W_{m}\left(\omega_{1}, \omega_{2}\right)\left[\left|H_{d}\left(\omega_{1}, \omega_{2}\right)\right|-\left|H\left(e^{j \omega_{1}}, e^{j \omega_{2}}\right)\right|^{\rho}\right]
\end{aligned}
$$

where $W_{m}\left(\omega_{1}, \omega_{2}\right)$ is a preset magnitude weighting function and $\rho=1$ or 2 depends on whether a causal or two-pass zerophase filter is to be designed. If constant group delay characteristic is considered in the design, we define the group delay errors as follows:

$$
\varepsilon_{g_{1}}\left(\omega_{1}, \omega_{2}\right) \triangleq W_{g}\left(\omega_{1}, \omega_{2}\right)\left[G D 1\left\{H\left(e^{j \omega_{1}}, e^{j \omega_{2}}\right)\right\}-g_{d_{1}}\right]
$$

and

$$
\varepsilon_{g_{2}}\left(\omega_{1}, \omega_{2}\right) \triangleq W_{g}\left(\omega_{1}, \omega_{2}\right)\left[G D 2\left\{H\left(e^{j \omega_{1}}, e^{j \omega_{2}}\right)\right\}-g_{d_{2}}\right]
$$

where $G D 1\{x\}$ and $G D 2\{x\}$ are the group delays of $x$ along $\omega_{1}$ and $\omega_{2}$ axes, respectively. In addition, we calculate a stability error $\varepsilon_{s, i}(m, n)$ in the spatial domain from a spectral factorization of the filter denominator's square magnitude. It is given by

$$
\varepsilon_{s, i}(m, n)=d_{i}(m, n)-d_{s, i}(m, n)
$$

where $d_{s, i}(m, n)$ denotes the causal spectral factor of $\left|D_{i}\left(e^{j \omega_{1}}, e^{j \omega_{2}}\right)\right|^{2}$ for $i=1,2,3,4$. Accordingly, we formulate the objective function as follows:

$$
\begin{aligned}
E= & \gamma_{m}\left\|\varepsilon_{m}\left(\omega_{1}, \omega_{2}\right)\right\|^{2}+\gamma_{g_{1}}\left\|\varepsilon_{g_{1}}\left(\omega_{1}, \omega_{2}\right)\right\|^{2} \\
& +\gamma_{g_{2}}\left\|\varepsilon_{g_{2}}\left(\omega_{1}, \omega_{2}\right)\right\|^{2} \\
& +\gamma_{s_{1}}\left\|\varepsilon_{s, 1}(m, n)\right\|^{2}+\gamma_{s_{2}}\left\|\varepsilon_{s, 2}(m, n)\right\|^{2} \\
& +\gamma_{s_{3}}\left\|\varepsilon_{s, 3}(m, n)\right\|^{2}+\gamma_{s_{4}}\left\|\varepsilon_{s, 4}(m, n)\right\|^{2}
\end{aligned}
$$

where $\|\mathrm{x}\|^{2}$ denotes the squared norm of $\mathrm{x}$. The parameters $\gamma_{m}$, $\gamma_{g_{1}}, \gamma_{g_{2}}, \gamma_{s_{1}}, \gamma_{s_{2}}, \gamma_{s_{3}}$, and $\gamma_{s_{4}}$ represent the relative weights between the squared error terms.

\section{B. Iterative Procedure}

Here, we present a design technique based on the spectral factorization method of [11] in conjunction with the trust-region Newton-conjugate gradient method [15], [16] for solving the nonlinear minimization problem of (34). The main idea of a trust-region Newton-conjugate gradient method is to define a region around the current iterate within which they trust the model function $m_{k}(\mathbf{s})$ to be an adequate reflection of the behavior of an objective function $f(\mathbf{x})$ around $\mathbf{x}_{k}$, and then choose the step $\mathbf{s}_{k}$ to be the approximate minimizer of the model in this trust region. The trust region is adjusted from iteration to iteration. If the model function $m_{k}$ is considered to be a good approximation to the objective function $f$, the trust region is safe to be expanded for the next iteration. Otherwise, the region should be reduced. Compared with the conventional line search algorithms like the Levenberg-Marquardt algorithm used in [11] and [12], a trust-region method does not require additional step size calculation. Importantly, when $\mathbf{x}_{k}$ is far from the solution, a negative curvature is often encountered. The trust-region Newton-conjugate gradient method will perform a long step $\mathbf{s}_{k}$ and move away rapidly from nonminimizing stationary points. In contrast, other gradient-based algorithms will slow down dramatically. It is noted that derivatives are needed to solve the step $\mathbf{s}_{k}$ within the trust region. Generally, if analytic derivatives are not provided, the conventional approximation techniques compute the derivatives numerically. Hence, they would increase the computational cost and would be very sensitive to numerical error. Therefore, we provide the analytic derivatives in the Appendix to avoid computing the derivatives numerically.

The iterative design technique is summarized step by step as follows.

Step 1) Specify the ideal magnitude $\left|H_{d}\left(\omega_{1}, \omega_{2}\right)\right|$, the size of discrete-time Fourier transform (DFT) $L \times L$, magnitude weighting $W_{m}\left(\omega_{1}, \omega_{2}\right)$, group delay weighting $W_{g}\left(\omega_{1}, \omega_{2}\right)$, relative weights $\gamma_{m}, \gamma_{g_{1}}$, $\gamma_{g_{2}}, \gamma_{s_{1}}, \gamma_{s_{2}}, \gamma_{s_{3}}, \gamma_{s_{4}}$, and filter orders $M_{i} \times N_{i}$.

Step 2) At the initial stage, we set ${ }^{(0)} d_{i}(m, n)=\delta(m, n)$ which is the unit impulse function, and the iteration number $k=0$.

Step 3) At the $k$ th iteration, we compute the magnitude response $\left.\left.\right|^{(k)} H\left(e^{j \omega_{1}}, e^{j \omega_{2}}\right)\right|^{\rho}$, group delay responses $G D 1\left({ }^{(k)} H\left(e^{j \omega_{1}}, e^{j \omega_{2}}\right)\right)$ and $G D 2\left({ }^{(k)} H\left(e^{j \omega_{1}}, e^{j \omega_{2}}\right)\right)$.

Step 4) Compute the difference between $\left|{ }^{(k)} H\left(e^{j \omega_{1}}, e^{j \omega_{2}}\right)\right|^{\rho} \quad$ and $\left|H_{d}\left(\omega_{1}, \omega_{2}\right)\right|$ over a finite set of discrete frequencies $\left(\omega_{1}, \omega_{2}\right)$, the difference between $G D 1\left({ }^{(k)} H\left(e^{j \omega_{1}}, e^{j \omega_{2}}\right)\right)$ and the desired group delay $g_{d_{1}}$, and the difference between $G D 2\left({ }^{(k)} H\left(e^{j \omega_{1}}, e^{j \omega_{2}}\right)\right)$ and the desired group delay $g_{d_{2}}$, respectively.

Step 5) Compute the spectral factor ${ }^{(k)} d_{s, i}(m, n)$ of $\left.{ }^{(k)} D_{i}\left(e^{j \omega_{1}}, e^{j \omega_{2}}\right)\right|^{2}$ and the difference between ${ }^{(k)} d_{s, i}(m, n)$ and ${ }^{(k)} d_{i}(m, n)$ over a finite index set $(m, n)$.

Step 6) Form the objective function $E$ according to (34) by stacking the scaled magnitude, group delay, and stability errors.

Step 7) Utilize the trust-region Newton-conjugate gradient optimization method with the function lsqnonlin() provided by Matlab Optimization Toolbox and the analytic derivatives provided in the Appendix to update $^{(k)} d_{i}(m, n)$.

Step 8) If $k=$ It max, where It max is a preset maximum number of iterations, then the design process is terminated. Otherwise, set $k=k+1$ and go to Step 3 .

Here, we explain the reasons why the unit impulse function is used as the initial guess in Step 2) as follows. a) Some existing techniques create the initial guess by performing SVD or inverse Fourier transform on the desired frequency response $H_{d}\left(e^{j \omega_{1}}, e^{j \omega_{2}}\right)$. However, several DAFs are involved in the proposed structure given by (13) and their respective desired responses are required when applying the above initialization methods. It is appropriate to use the unit impulse function as 
TABLE V

DESIGN PARAMETERS

\begin{tabular}{|l|c|c|c|c|c|c|c|c|}
\hline & $\gamma_{m}$ & $\gamma_{g_{1}}$ & $\gamma_{g_{2}}$ & $\gamma_{s_{1}}$ & $\gamma_{s_{2}}$ & $\gamma_{s_{3}}$ & $\gamma_{s_{4}}$ & $\rho$ \\
\hline Example 1 & 0.99 & 0 & 0 & 1000 & 1000 & 0 & 0 & 2 \\
\hline Example 2 & $1 \times 10^{10}$ & $1 \times 10^{10}$ & $1 \times 10^{10}$ & 1 & 1 & 1 & 1 & 1 \\
\hline Example 3 & $1 \times 10^{4}$ & 5 & 5 & $1 \times 10^{7}$ & $1 \times 10^{7}$ & $1 \times 10^{7}$ & $1 \times 10^{7}$ & 1 \\
\hline Example 4 & $1 \times 10^{6}$ & 0.98 & 0.98 & $1 \times 10^{5}$ & $1 \times 10^{5}$ & $1 \times 10^{5}$ & $1 \times 10^{5}$ & 1 \\
\hline
\end{tabular}

the initial guess for each denominator $D_{i}\left(z_{1}, z_{2}\right)$; hence, only the desired response $H_{d}\left(e^{j \omega_{1}}, e^{j \omega_{2}}\right)$ is required. b) For stabilization, it is noted that the transfer function of ${ }^{(0)} d_{i}(m, n)=\delta(m, n)$ is ${ }^{(0)} D_{i}\left(z_{1}, z_{2}\right)=1$ and its stability is, thus, guaranteed. c) If a linear phase or constant group delay design is considered. The initial response of $H\left(z_{1}, z_{2}\right)$ is given by ${ }^{(0)} H\left(e^{j \omega_{1}}, e^{j \omega_{2}}\right)=e^{-j g_{d_{1}} \omega_{1}} e^{-j g_{d_{2}} \omega_{2}}$ for all $\left(\omega_{1}, \omega_{2}\right)$. It approximates the specified frequency response in the passband.

\section{Simulation Results}

The design examples were performed on a PC with Pentium-IV CPU using MATLAB programming language. For comparison, some significant design results are defined as follows.

Passband magnitude mean-squared errors (PMSE)

PMSE

$$
=\sum \sum_{\left(\omega_{1}, \omega_{2}\right) \in \Omega_{p}} \frac{\left(\left|H\left(e^{j \omega_{1}}, e^{j \omega_{2}}\right)\right|^{\rho}-\left|H_{d}\left(\omega_{1}, \omega_{2}\right)\right|\right)^{2}}{\text { number of grid points in the passband }}
$$

where $\Omega_{p}$ is the set of grid points in the passband.

Stopband magnitude mean-squared errors (SMSE)

\section{SMSE}

$$
=\sum \sum_{\left(\omega_{1}, \omega_{2}\right) \in \Omega_{s}} \frac{\left(\left|H\left(e^{j \omega_{1}}, e^{j \omega_{2}}\right)\right|^{\rho}-\left|H_{d}\left(\omega_{1}, \omega_{2}\right)\right|\right)^{2}}{\text { number of grid points in the stopband }}
$$

where $\Omega_{s}$ is the set of grid points in the stopband.

Passband phase mean-squared errors (PPMSE)

PPMSE

$$
=\sum \sum_{\left(\omega_{1}, \omega_{2}\right) \in \Omega_{p}} \frac{\left[\arg \left\{H\left(e^{j \omega_{1}}, e^{j \omega_{2}}\right)\right\}-\arg \left\{e^{-j\left(g_{d_{1}} \omega_{1}+g_{d_{2}} \omega_{2}\right)}\right\}\right]^{2}}{\text { number of grid points in the passband }}
$$

where $\arg \{x\}$ denotes the phase response of $x$.
Peak stability error (PSE) of $A_{i}\left(z_{1}, z_{2}\right)$

$$
\mathrm{PSE}_{i}=\max \left|\varepsilon_{s, i}(m, n)\right| \text { for } 1 \leq i \leq 4
$$

Passband ripple $(\mathrm{dB})$

$$
\mathrm{PR}=\max _{\left(\omega_{1}, \omega_{2}\right) \in \Omega_{p}}\left|20 \log _{10}\left(\left|H\left(e^{j \omega_{1}}, e^{j \omega_{2}}\right)\right|\right)\right|
$$

Stopband attenuation $(\mathrm{dB})$

$$
\mathrm{SA}=-\max _{\left(\omega_{1}, \omega_{2}\right) \in \Omega_{s}} 20 \log _{10}\left(\left|H\left(e^{j \omega_{1}}, e^{j \omega_{2}}\right)\right|\right)
$$

Peak relative group delays

$$
\begin{aligned}
\text { PRGD1 } & =\frac{\max _{\left(\omega_{1}, \omega_{2}\right) \in \Omega_{p}}\left(\left|G D 1\left(H\left(e^{j \omega_{1}}, e^{j \omega_{2}}\right)\right)-g_{d_{1}}\right|\right)}{g_{d_{1}}} \\
\operatorname{mRGD2} & =\frac{\max _{\left(\omega_{1}, \omega_{2}\right) \in \Omega_{p}}\left(\left|G D 2\left(H\left(e^{j \omega_{1}}, e^{j \omega_{2}}\right)\right)-g_{d_{2}}\right|\right)}{g_{d_{2}}} .
\end{aligned}
$$

1) Example 1: A $\pm 45^{\circ}$ Fan Filter: The $\pm 45^{\circ}$ fan filter is specified by letting $g=1$ in (23). To achieve a zero phase design, we set $\rho=2$ in (30). The orders of two recursive NSHP DAFs are $M_{1} \times N_{1}=3 \times 2$ and $M_{2} \times N_{2}=3 \times 3$, respectively. The magnitude weighting function $W_{m}\left(\omega_{1}, \omega_{2}\right)$ is set to the equation shown at the bottom of the page.

The other design parameters required are shown in Table V. The resulting magnitude-squared response for this design is plotted in Fig. 9. For comparison, the same fan filter based on the conventional 2-D IIR NSHP filter of [11] is also designed by using the trust-region Newton-conjugate gradient method. The size of 2-D DFT used is $32 \times 32$ and the number of iterations is 25 for both designs. The significant design results, namely PMSE, SMSE, and $\mathrm{PSE}_{i}$ are shown in Table VI. We note that the proposed technique provides very satisfactory design results.

$$
W_{m}\left(\omega_{1}, \omega_{2}\right)= \begin{cases}1 & \tan \left(\frac{\pi}{4-0.1}\right) \cdot\left|\omega_{1}\right|>\left|\omega_{2}\right| \text { and } \omega_{1} \geq 0 \\ 1 & \tan \left(\frac{\pi}{4+0.1}\right) \cdot\left|\omega_{1}\right|<\left|\omega_{2}\right| \text { and } \omega_{1} \geq 0 \\ 0 & \tan \left(\frac{\pi}{4-0.1}\right) \cdot\left|\omega_{1}\right| \leq\left|\omega_{2}\right|, \tan \left(\frac{\pi}{4+0.1}\right) \cdot\left|\omega_{1}\right| \geq\left|\omega_{2}\right|, \text { and } \omega_{1} \geq 0\end{cases}
$$


TABLE VI

SIGNIFICANT DESIGN RESULTS FOR EXAMPLE 1

\begin{tabular}{|c|c|c|c|c|}
\hline Design Methods & PMSE & SMSE & PSE $_{\mathrm{i}}$ & $\begin{array}{c}\text { Number of } \\
\text { Independent } \\
\text { Coefficients }\end{array}$ \\
\hline $\begin{array}{c}\text { conventional } \\
\text { NSHP Filter }\end{array}$ & $6.099 \times 10^{-4}$ & $4.096 \times 10^{-3}$ & $4.403 \times 10^{-6}$ & 41 \\
\hline Proposed Technique & $5.222 \times 10^{-7}$ & $9.918 \times 10^{-7}$ & $\begin{array}{l}1.631 \times 10^{-5} \\
1.044 \times 10^{-4}\end{array}$ & 43 \\
\hline
\end{tabular}

TABLE VII

Filter COEFFICIENTS OF THE $30^{\circ}$ FAN Filter. (a) COEFFICIENTS OF $A_{1}\left(z_{1}, z_{2}\right)$. (b) CoEFFiCIENTS OF $A_{2}\left(z_{1}, z_{2}\right)$. (c) COEFFICIENTS OF $A_{3}\left(z_{1}, z_{2}\right)$. (d) COEFFICIENTS OF $A_{4}\left(z_{1}, z_{2}\right)$

\begin{tabular}{|c|c|c|c|c|c|}
\hline-0.07532549 & -0.04129947 & 0.06868830 & 0.02855055 & 0.04385812 & -0.01895588 \\
\hline 0.03420936 & -0.01768154 & $\begin{array}{l}0.19414512 \\
1.01968932\end{array}$ & $\begin{array}{r}0.01673802 \\
-0.06483671\end{array}$ & $\begin{array}{r}-0.11035891 \\
0.01932101\end{array}$ & $\begin{array}{c}-0.00755557 \\
0.01276331\end{array}$ \\
\hline
\end{tabular}

(a)

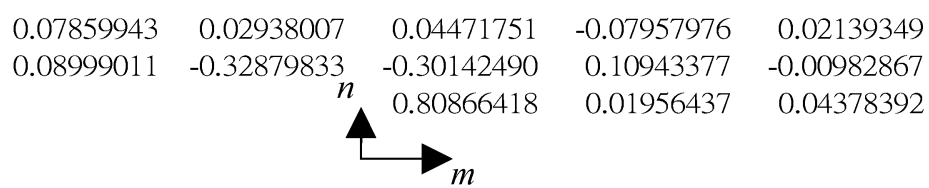

(b)

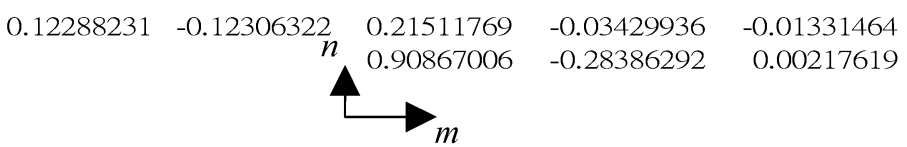

(c)

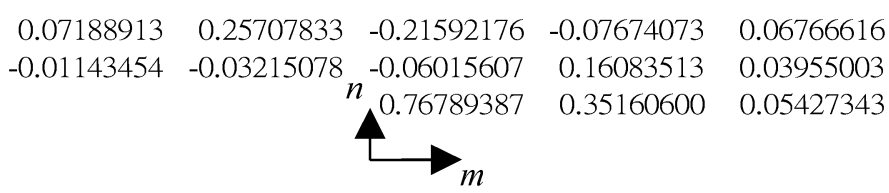

(d)

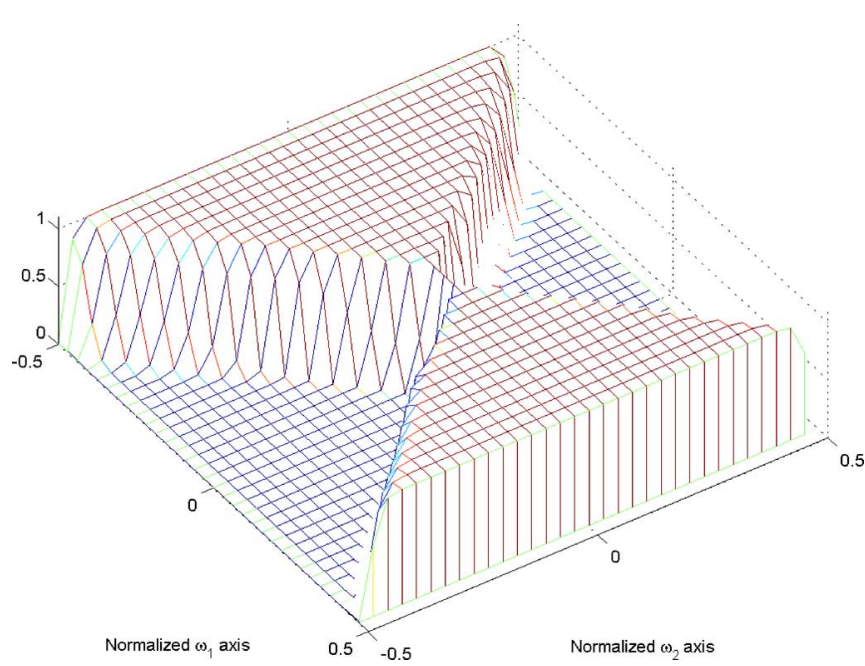

Fig. 9. Magnitude-squared response of the designed filter for Example 1.

2) Example 2: A $30^{\circ}$ Fan Filter: Here, the $30^{\circ}$ fan filter with design specification is shown in Fig. 8. The orders of four
NSHP DAFs are set to $M_{1} \times N_{1}=3 \times 2, M_{2} \times N_{2}=$ $2 \times 2, M_{3} \times N_{3}=2 \times 1$, and $M_{4} \times N_{4}=2 \times 2$, respectively. According to (26) and (27), the ideal group delays are set to $g_{d_{1}}=4.5$ and $g_{d_{2}}=3.5$, respectively. The magnitude weighting function $W_{m}\left(\omega_{1}, \omega_{2}\right)$ is chosen as follows: $W_{m}\left(\omega_{1}, \omega_{2}\right)=2$ in the passband, $W_{m}\left(\omega_{1}, \omega_{2}\right)=1$ in the stopband, and $W_{m}\left(\omega_{1}, \omega_{2}\right)=0$ in the transition band. We set the group delay weighting function $W_{g}\left(\omega_{1}, \omega_{2}\right)=1$ only in the passband. Table $\mathrm{V}$ lists the parameters required for this design. Table VII lists the filter coefficients obtained by using the proposed technique. The largest $\mathrm{PSE}_{i}$ is $3.099 \times 10^{-10}$. Fig. 10 depicts the magnitude response of the designed 2-D recursive filter. Table VIII presents the comparison between the significant design results by using the proposed technique and the method of [12]. The size of 2-D DFT used is $32 \times 32$ and the number of iterations is 10 for both designs.

3) Example 3: A Circularly Symmetric Lowpass Filter: Here, we consider the same design case as that given by [24] and [25]. The desired frequency response is given by (28), where the passband and stopband edges are $\omega_{p}=0.5 \pi$ and $\omega_{s}=$ 
TABLE VIII

SIGNIFICANT DESIGN RESULTS FOR EXAMPLE 2

\begin{tabular}{|c|c|c|c|c|}
\hline Design Methods & PMSE & SMSE & PPMSE & $\begin{array}{c}\text { Number of Independent } \\
\text { Coefficients }\end{array}$ \\
\hline$[12]$ & $1.244 \times 10^{-2}$ & $7.376 \times 10^{-4}$ & $2.408 \times 10^{-3}$ & 57 \\
\hline Proposed Technique & $1.567 \times 10^{-4}$ & $3.161 \times 10^{-4}$ & $4.397 \times 10^{-5}$ & 52 \\
\hline
\end{tabular}

TABLE IX

SIGNIFICANT DESIGN RESULTS FOR EXAMPLE 4

\begin{tabular}{|c|c|c|c|c|c|}
\hline Design Methods & PR & SA & PRGD & $\begin{array}{c}\text { Number of Independent } \\
\text { Coefficients }\end{array}$ & $\begin{array}{c}\text { Number of } \\
\text { Iterations }\end{array}$ \\
\hline$[23]$ & 0.0312 & 36.05 & 0.1030 & 247 & 55 \\
\hline $\begin{array}{c}\text { Proposed } \\
\text { Technique }\end{array}$ & 0.0061 & 55.54 & 0.0752 & 244 & 55 \\
\hline
\end{tabular}

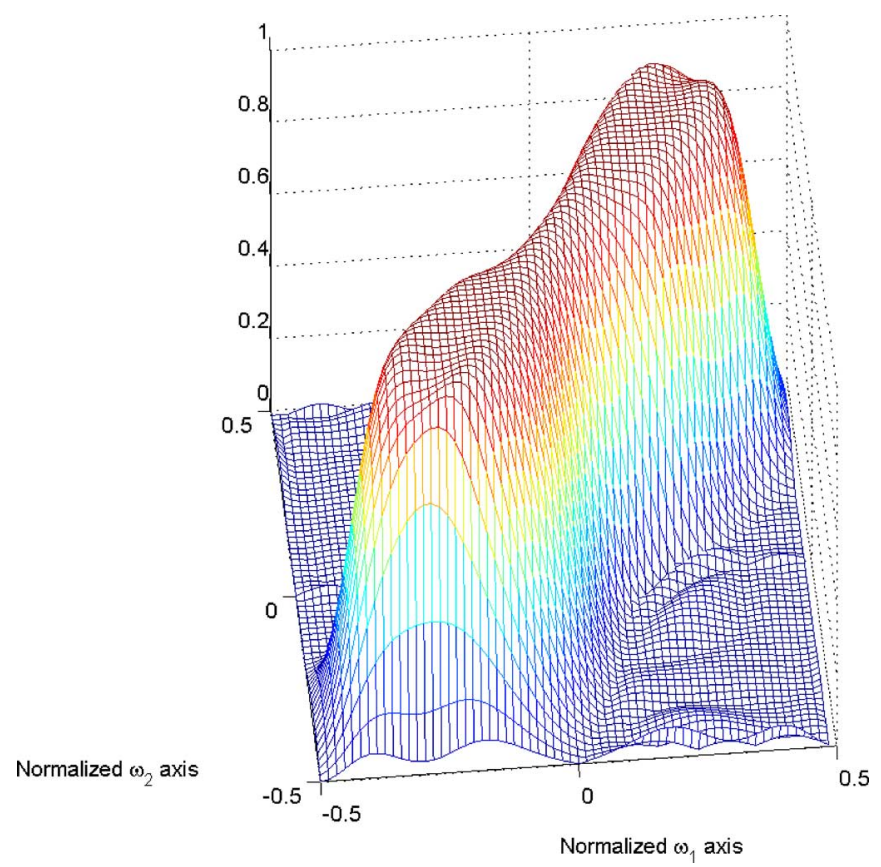

Fig. 10. Magnitude response of the designed filter for Example 2.

$0.7 \pi$, respectively. The required design parameters are listed in Table V. The magnitude weighting function $W_{m}\left(\omega_{1}, \omega_{2}\right)$ is chosen as follows: $W_{m}\left(\omega_{1}, \omega_{2}\right)=1$ in the passband and stopband, $W_{m}\left(\omega_{1}, \omega_{2}\right)=0$ in the transition band. We set the group delay weighting function $W_{g}\left(\omega_{1}, \omega_{2}\right)=1$ only in the passband. For comparison, the structure given by (25) is adapted to approximate the desired lowpass characteristics and the orders of four NSHP DAFs are set to $M_{1} \times N_{1}=2 \times 3, M_{2} \times N_{2}=3 \times 3$, $M_{3} \times N_{3}=3 \times 3$, and $M_{4} \times N_{4}=3 \times 4$, respectively. Accordingly, the ideal group delay responses are $g_{d_{1}}=5.5$ and $g_{d_{2}}=6.5$, respectively. The group delay may have an arbitrary value in [24] and [25]. The number of independent coefficients is 100 for our design and it is 99 for the designs of [24] and [25]. The size of 2-D DFT used in computing the stability errors is $32 \times 32$. The $\left(\omega_{1}, \omega_{2}\right)$ plane is uniformly sampled with a $46 \times 46$ grid density, and, therefore, 907 grid points are used in the passband and stopband; 45 iterations are taken by the proposed technique to achieve the design result shown in Fig. 11. The proposed technique shows satisfactory design capability as compared with the technique of [25]: 43.6- versus

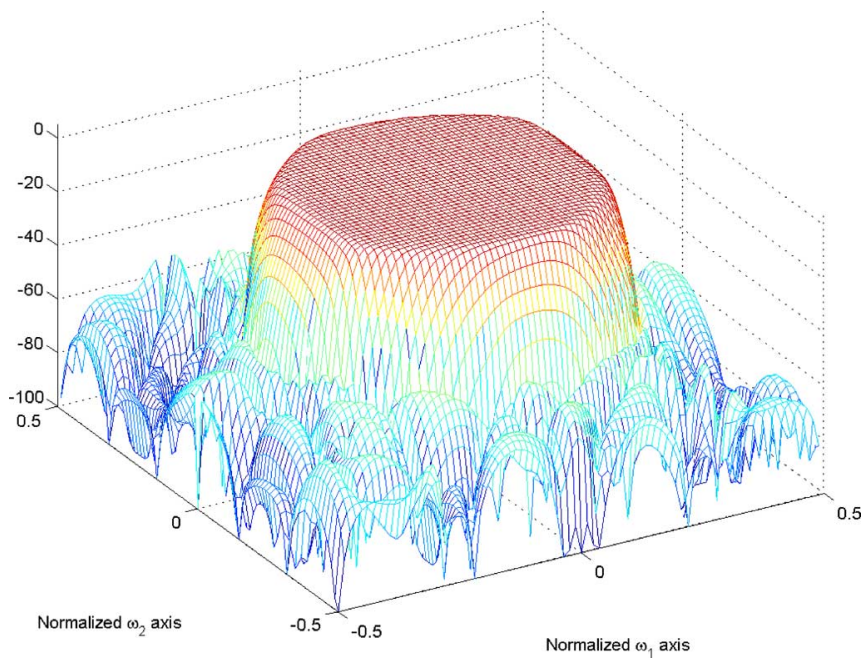

Fig. 11. Magnitude response of the designed filter for Example 3.

42.5-dB stopband attenuation; 0.0046 versus 0.0074 maximum magnitude deviation in the passband; 0.567 versus 0.526 maximum group delay error in the passband. Some additional significant results obtained using the proposed technique are given as follows: $\mathrm{PMSE}=1.116 \times 10^{-6}, \mathrm{SMSE}=2.282 \times 10^{-6}$, and the largest $\mathrm{PSE}_{i}$ is $4.715 \times 10^{-7}$.

4) Example 4: A Diamond-Shaped Lowpass Filter: This example is the same as that given by [23]. The desired frequency response of the diamond-shaped lowpass filter is shown by (29) with the passband and stopband edge frequencies $\omega_{p}=0.8 \pi$ and $\omega_{s}=\pi$, respectively. The magnitude weighting function $W_{m}\left(\omega_{1}, \omega_{2}\right)$ is chosen as follows: $W_{m}\left(\omega_{1}, \omega_{2}\right)=1$ in the passband and stopband, $W_{m}\left(\omega_{1}, \omega_{2}\right)=0$ in the transition band. We set the group delay weighting function $W_{g}\left(\omega_{1}, \omega_{2}\right)=1$ only in the passband. The structure given by (25) is adapted to approximate the desired lowpass characteristics and the orders of four NSHP DAFs are set to $M_{1} \times N_{1}=5 \times 5, M_{2} \times N_{2}=$ $6 \times 5, M_{3} \times N_{3}=5 \times 4$, and $M_{4} \times N_{4}=5 \times 5$, respectively. Accordingly, the ideal group delay responses are $g_{d_{1}}=10.5$ and $g_{d_{2}}=9.5$, respectively. The group delay may have an arbitrary value in [23]. The size of 2-D DFT used in computing the stability errors is $32 \times 32$. The $\left(\omega_{1}, \omega_{2}\right)$ plane is uniformly sampled with a $48 \times 48$ grid density, and, therefore, 1008 grid points 
TABLE X

FiLTER COEFFICIENTS OF THE DiAMOND-SHAPED LOWPASS FiLTER. (a) COEFFICIENTS OF $A_{1}\left(z_{1}, z_{2}\right)$. (b) COEFFICIENTS OF $A_{2}\left(z_{1}, z_{2}\right)$. (c) COEFFICIENTS OF $A_{3}\left(z_{1}, z_{2}\right)$. (d) COEFFICIENTS OF $A_{4}\left(z_{1}, z_{2}\right)$.

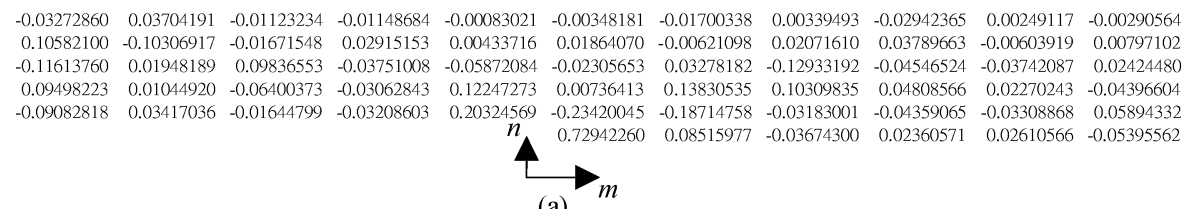

(a)

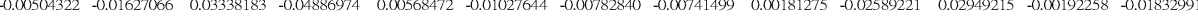
$\begin{array}{llllllllllllll}-0.00839314 & 0.07342108 & -0.09068907 & 0.07082851 & 0.01305863 & 0.00515118 & 0.01829259 & -0.00180685 & 0.03664779 & -0.00826172 & -0.07758723 & 0.01794326 & 0.05405356\end{array}$

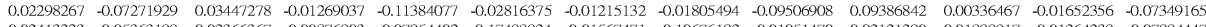

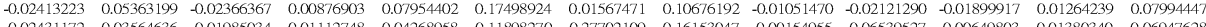

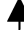

(b)

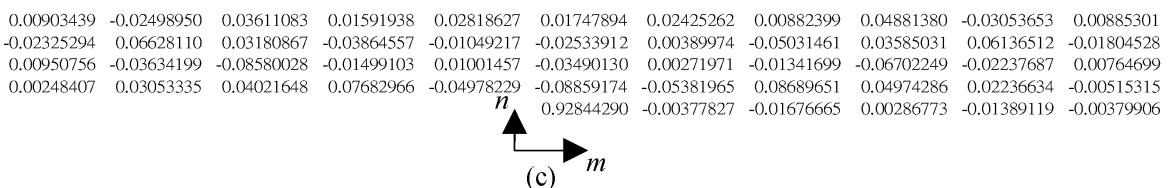

(c)

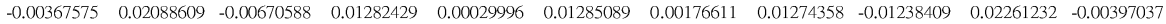
$\begin{array}{llllllllllll}0.02582987 & -0.04019665 & 0.02132857 & 0.03862535 & 0.00753492 & 0.01945025 & -0.00241543 & 0.03692866 & 0.03297264 & -0.04135324 & 0.02478797\end{array}$ $\begin{array}{lllllllllll}-0.03006897 & 0.03865718 & 0.04788245 & -0.05563640 & -0.07116962 & -0.03475154 & -0.05909912 & -0.05983885 & 0.05878943 & 0.03396790 & -0.02187799\end{array}$

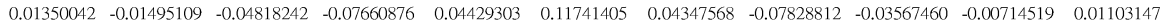
$\begin{array}{llllllllllll}0.00511201 & 0.01805552 & 0.03303704 & 0.08201623 & 0.23214921 & -0.17312861 & 0.22462618 & 0.09265000 & 0.02622032 & 0.01732476 & -0.00434305\end{array}$ $\begin{array}{lllllll}n & 0.57831305 & -0.00495579 & -0.00867852 & -0.00297063 & -0.00538018 & -0.00338839\end{array}$

(d)

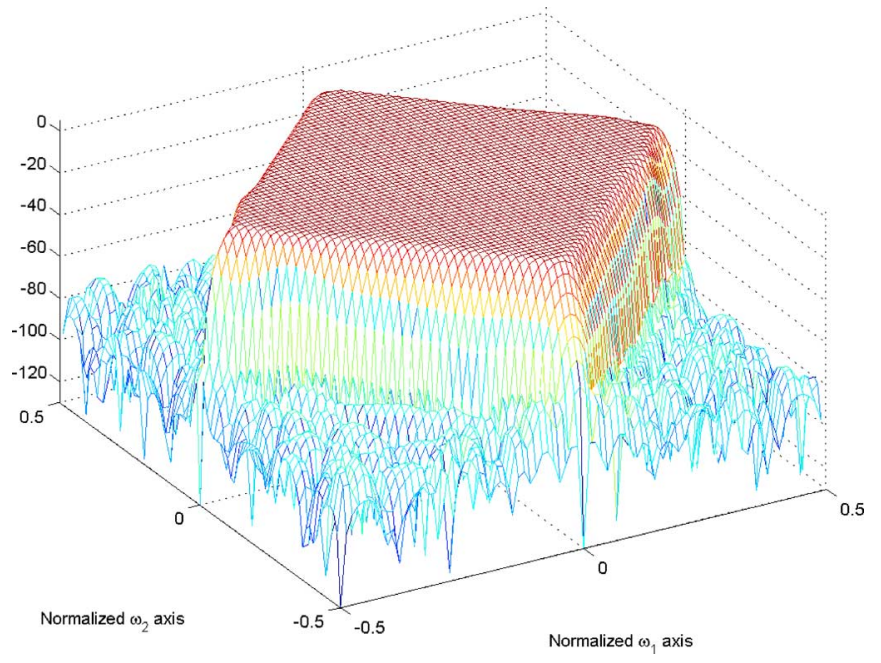

Fig. 12. Magnitude response of the designed filter for Example 4.

are used in the passband and stopband. The significant design results and the iteration number required by using the technique of [23] and the proposed technique are shown in Table IX for comparison. Table $\mathrm{X}$ lists the filter coefficients obtained by using the proposed technique. The largest $\mathrm{PSE}_{i}$ is $3.582 \times 10^{-6}$. Fig. 12 shows the magnitude response of the designed diamond-shaped lowpass filter. The proposed technique performs significantly better than the technique of [23]. Some additional significant results obtained using the proposed technique are given as follows: $\mathrm{PMSE}=2.953 \times 10^{-8}$, $\mathrm{SMSE}=9.157 \times 10^{-8}$.

In (34), there are two major aspects, approximation and stabilization, woven into the optimization process simultaneously. In order to ensure the stability of designed filters, $\gamma_{s_{i}}$ should be selected large enough to keep $\varepsilon_{s, i} \simeq 0$. The weights $\gamma_{m}$ and $\gamma_{g i}$ would be increased to obtain better magnitude and group delay approximation results. On the other hand, the ratio $\gamma_{g i} / \gamma_{m}$ is highly dependent on the desired group delay and it should be larger when designing 2-D recursive filters with smaller group delay responses. The weights listed in Table $\mathrm{V}$ are the experimental results and they provide a satisfactory approximation to the desired specifications, i.e., the performances between magnitude responses and phase/group delay responses are balanced.

\section{CONCLUSION}

This paper has presented the theoretical work on the design of 2-D recursive digital filters using 2-D recursive DAFs with NSHP coefficient support. The 2-D recursive NSHP DAFs are used as the building blocks to construct 2-D recursive digital filters. The resulting 2-D recursive NSHP digital filters possess general approximation capabilities. As to the problem for designing 2-D stable recursive NSHP digital filters, an objective function consists of the weighted sum of magnitude, group delay, and stability errors has been formulated. Accordingly, the derivatives of the objective function required for solving the design problem can be computed analytically. The novelty of the research work has been shown by several design examples.

\section{APPENDIX}

Here, we derive the analytic derivatives for each error term in the objective function of (34). Let the vector $\mathbf{d}_{i}=\left[d_{i}(m, n)\right]$ contain the filter coefficients. For $\rho=2$, the magnitude error is given by

$$
\begin{aligned}
& \varepsilon_{m}\left(\omega_{1}, \omega_{2}\right) \\
& \triangleq W_{m}\left(\omega_{1}, \omega_{2}\right)\left[\left|H_{d}\left(\omega_{1}, \omega_{2}\right)\right|-\left|H\left(e^{j \omega_{1}}, e^{j \omega_{2}}\right)\right|^{2}\right] \\
& =W_{m}\left(\omega_{1}, \omega_{2}\right)\left[\left|H_{d}\left(\omega_{1}, \omega_{2}\right)\right|-H\left(e^{j \omega_{1}}, e^{j \omega_{2}}\right) H^{*}\left(e^{j \omega_{1}}, e^{j \omega_{2}}\right)\right]
\end{aligned}
$$

where $H\left(e^{j \omega_{1}}, e^{j \omega_{2}}\right)$ is the frequency response of (24). 
The analytic derivatives of magnitude error with respect to the filter coefficients are given by

$$
\begin{aligned}
& \frac{\partial \varepsilon_{m}\left(\omega_{1}, \omega_{2}\right)}{\partial \mathbf{d}_{i}} \\
& =-W_{m}\left(\omega_{1}, \omega_{2}\right)\left[\frac{1}{2} \frac{\partial A_{i}\left(e^{j \omega_{1}}, e^{j \omega_{2}}\right)}{\partial \mathbf{d}_{i}}\right. \\
& \left.\times H^{*}\left(e^{j \omega_{1}}, e^{j \omega_{2}}\right)+H\left(e^{j \omega_{1}}, e^{j \omega_{2}}\right) \times \frac{1}{2} \frac{\partial A_{i}^{*}\left(e^{j \omega_{1}}, e^{j \omega_{2}}\right)}{\partial \mathbf{d}_{i}}\right] \\
& =-W_{m}\left(\omega_{1}, \omega_{2}\right) \times \operatorname{Re}\left\{\frac{\partial A_{i}\left(e^{j \omega_{1}}, e^{j \omega_{2}}\right)}{\partial \mathbf{d}_{i}} H^{*}\left(e^{j \omega_{1}}, e^{j \omega_{2}}\right)\right\}
\end{aligned}
$$

where

$$
\begin{aligned}
\frac{\partial A_{i}\left(e^{j \omega_{1}}, e^{j \omega_{2}}\right)}{\partial d_{i}\left(m^{\prime}, n^{\prime}\right)}= & \frac{\partial}{\partial d_{i}\left(m^{\prime}, n^{\prime}\right)} e^{-j M_{i} \omega_{1}} e^{-j N_{i} \omega_{2}} \\
& \cdot \frac{\sum_{m} \sum_{n} d_{i}(m, n) e^{j m \omega_{1}} e^{j n \omega_{2}}}{\sum_{m} \sum_{n} d_{i}(m, n) e^{-j m \omega_{1}} e^{-j n \omega_{2}}} \\
= & e^{-j M_{i} \omega_{1} e^{-j N_{i} \omega_{2}}} \\
& \cdot \frac{2 j \operatorname{Im}\left\{e^{j\left(m^{\prime} \omega_{1}+n^{\prime} \omega_{2}\right)} D_{i}\left(e^{j \omega_{1}}, e^{j \omega_{2}}\right)\right\}}{D_{i}^{2}\left(e^{j \omega_{1}}, e^{j \omega_{2}}\right)} .
\end{aligned}
$$

Thus, see equation (A4), shown at the bottom of the page. For $\rho=1$, the magnitude error is given by

$$
\begin{aligned}
& \varepsilon_{m}\left(\omega_{1}, \omega_{2}\right) \\
& \quad \triangleq W_{m}\left(\omega_{1}, \omega_{2}\right)\left[\left|H_{d}\left(\omega_{1}, \omega_{2}\right)\right|-\left(\left|H\left(e^{j \omega_{1}}, e^{j \omega_{2}}\right)\right|^{2}\right)^{1 / 2}\right]
\end{aligned}
$$

where $H\left(e^{j \omega_{1}}, e^{j \omega_{2}}\right)$ is the frequency response of (25). This expression is differentiable except at points for which $H\left(e^{j \omega_{1}}, e^{j \omega_{2}}\right)=0$. With the exception of these points

$$
\begin{aligned}
& \frac{\partial \varepsilon_{m}\left(\omega_{1}, \omega_{2}\right)}{\partial \mathbf{d}_{i}} \\
& =-\frac{W_{m}\left(\omega_{1}, \omega_{2}\right)}{2\left|H\left(e^{j \omega_{1}}, e^{j \omega_{2}}\right)\right|}\left[\frac{\partial H\left(e^{j \omega_{1}}, e^{j \omega_{2}}\right) H^{*}\left(e^{j \omega_{1}}, e^{j \omega_{2}}\right)}{\partial \mathbf{d}_{i}}\right] .
\end{aligned}
$$

From (A3), we have (A7), shown at the bottom of the page. Similarly, see (A8), shown at the bottom of the page.

The second and third terms in the objective function are the group delay errors along $\omega_{1}$ and $\omega_{2}$ axes, respectively. The derivatives of the group delay errors are derived as follows. The phase response of $H\left(e^{j \omega_{1}}, e^{j \omega_{2}}\right)$ in Examples 2, 3, and 4 is given by

$$
\begin{array}{r}
\arg \left\{H\left(e^{j \omega_{1}}, e^{j \omega_{2}}\right)\right\}=-g_{d_{1}} \omega_{1}-g_{d_{2}} \omega_{2}-\phi_{1}\left(\omega_{1}, \omega_{2}\right) \\
-\phi_{2}\left(\omega_{1}, \omega_{2}\right)-\phi_{3}\left(\omega_{1}, \omega_{2}\right)-\phi_{4}\left(\omega_{1}, \omega_{2}\right) .
\end{array}
$$

Thus, the group delay of $H\left(e^{j \omega_{1}}, e^{j \omega_{2}}\right)$ along $\omega_{1}$ axis is given by

$$
\begin{aligned}
G D 1 & \left\{H\left(e^{j \omega_{1}}, e^{j \omega_{2}}\right)\right\} \\
= & -\frac{\partial}{\partial \omega_{1}} \arg \left\{H\left(e^{j \omega_{1}}, e^{j \omega_{2}}\right)\right\} \\
= & g_{d_{1}}+\frac{\partial \phi_{1}\left(\omega_{1}, \omega_{2}\right)}{\partial \omega_{1}}+\frac{\partial \phi_{2}\left(\omega_{1}, \omega_{2}\right)}{\partial \omega_{1}}+\frac{\partial \phi_{3}\left(\omega_{1}, \omega_{2}\right)}{\partial \omega_{1}} \\
& +\frac{\partial \phi_{4}\left(\omega_{1}, \omega_{2}\right)}{\partial \omega_{1}} .
\end{aligned}
$$

$$
\frac{\partial \varepsilon_{m}\left(\omega_{1}, \omega_{2}\right)}{\partial d_{i}\left(m^{\prime}, n^{\prime}\right)}=-W_{m}\left(\omega_{1}, \omega_{2}\right) \times \operatorname{Re}\left\{e^{-j M_{i} \omega_{1}} e^{-j N_{i} \omega_{2}} \frac{2 j \operatorname{Im}\left\{e^{j\left(m^{\prime} \omega_{1}+n^{\prime} \omega_{2}\right)} D_{i}\left(e^{j \omega_{1}}, e^{j \omega_{2}}\right)\right\}}{D_{i}^{2}\left(e^{j \omega_{1}}, e^{j \omega_{2}}\right)} H^{*}\left(e^{j \omega_{1}}, e^{j \omega_{2}}\right)\right\}
$$

$$
\begin{aligned}
\frac{\partial \varepsilon_{m}\left(\omega_{1}, \omega_{2}\right)}{\partial d_{i}\left(m^{\prime}, n^{\prime}\right)}= & -\frac{W_{m}\left(\omega_{1}, \omega_{2}\right)}{\left|H\left(e^{j \omega_{1}}, e^{j \omega_{2}}\right)\right|} \\
& \times \operatorname{Re}\left\{e^{-j M_{i} \omega_{1}} e^{-j N_{i} \omega_{2}} \frac{j \operatorname{Im}\left\{e^{j\left(m^{\prime} \omega_{1}+n^{\prime} \omega_{2}\right)} D_{i}\left(e^{j \omega_{1}}, e^{j \omega_{2}}\right)\right\}}{D_{i}^{2}\left(e^{j \omega_{1}}, e^{j \omega_{2}}\right)} H^{*}\left(e^{j \omega_{1}}, e^{j \omega_{2}}\right) \times \frac{1}{2}\left[A_{3}\left(e^{j \omega_{1}}, e^{j \omega_{2}}\right)+A_{4}\left(e^{j \omega_{1}}, e^{j \omega_{2}}\right)\right]\right\} \\
& \text { for } \mathrm{i}=1,2
\end{aligned}
$$

$$
\begin{aligned}
\frac{\partial \varepsilon_{m}\left(\omega_{1}, \omega_{2}\right)}{\partial d_{i}\left(m^{\prime}, n^{\prime}\right)}= & -\frac{W_{m}\left(\omega_{1}, \omega_{2}\right)}{\mid H\left(e^{\left.j \omega_{1}, e^{j \omega_{2}}\right) \mid}\right.} \\
& \times \operatorname{Re}\left\{e^{-j M_{i} \omega_{1}} e^{-j N_{i} \omega_{2}} \frac{j \operatorname{Im}\left\{e^{j\left(m^{\prime} \omega_{1}+n^{\prime} \omega_{2}\right)} D_{i}\left(e^{j \omega_{1}}, e^{j \omega_{2}}\right)\right\}}{D_{i}^{2}\left(e^{j \omega_{1}}, e^{j \omega_{2}}\right)} H^{*}\left(e^{j \omega_{1}}, e^{j \omega_{2}}\right) \times \frac{1}{2}\left[A_{1}\left(e^{j \omega_{1}}, e^{j \omega_{2}}\right)+A_{2}\left(e^{j \omega_{1}}, e^{j \omega_{2}}\right)\right]\right\}
\end{aligned}
$$$$
\text { for } \mathrm{i}=3,4
$$ 


$$
\begin{aligned}
\frac{\partial \varepsilon_{g_{1}}\left(\omega_{1}, \omega_{2}\right)}{\partial d_{i}\left(m^{\prime}, n^{\prime}\right)}= & W_{g}\left(\omega_{1}, \omega_{2}\right) \frac{\partial}{\partial d_{i}\left(m^{\prime}, n^{\prime}\right)} \frac{\partial \phi_{i}\left(\omega_{1}, \omega_{2}\right)}{\partial \omega_{1}} \\
= & -W_{g}\left(\omega_{1}, \omega_{2}\right) \\
& \left\{\begin{array}{l}
{\left[\begin{array}{l}
\left(\cos \left(m^{\prime} \omega_{1}+n^{\prime} \omega_{2}\right) m^{\prime}\right)\left(\sum_{m} \sum_{n} d_{i}(m, n) \cos \left(m \omega_{1}+n \omega_{2}\right)\right) \\
+\left(\sum_{m} \sum_{n} d_{i}(m, n) \cos \left(m \omega_{1}+n \omega_{2}\right) m\right) \cos \left(m^{\prime} \omega_{1}+n^{\prime} \omega_{2}\right) \\
+\left(\sin \left(m^{\prime} \omega_{1}+n^{\prime} \omega_{2}\right) m^{\prime}\right)\left(\sum_{m} \sum_{n} d_{i}(m, n) \sin \left(m \omega_{1}+n \omega_{2}\right)\right) \\
+\left(\sum_{m} \sum_{n} d_{i}(m, n) \sin \left(m \omega_{1}+n \omega_{2}\right) m\right) \sin \left(m^{\prime} \omega_{1}+n^{\prime} \omega_{2}\right)
\end{array}\right] \mid D_{i}\left(e^{\left.j \omega_{1}, e^{j \omega_{2}}\right)\left.\right|^{2}}\right.} \\
-2\left[\left(\sum_{m} \sum_{n} d_{i}(m, n) \cos \left(m \omega_{1}+n \omega_{2}\right) m\right)\left(\sum_{m} \sum_{n} d_{i}(m, n) \cos \left(m \omega_{1}+n \omega_{2}\right)\right)\right. \\
\left.+\left(\sum_{m} \sum_{n} d_{i}(m, n) \sin \left(m \omega_{1}+n \omega_{2}\right) m\right)\left(\sum_{m} \sum_{n} d_{i}(m, n) \sin \left(m \omega_{1}+n \omega_{2}\right)\right)\right] \\
{\left[\begin{array}{l}
\left(\sum_{m} \sum_{n} d_{i}(m, n) \cos \left(m \omega_{1}+n \omega_{2}\right)\right) \cos \left(m^{\prime} \omega_{1}+n^{\prime} \omega_{2}\right) \\
+\left(\sum_{m} \sum_{n} d_{i}(m, n) \sin \left(m \omega_{1}+n \omega_{2}\right)\right) \sin \left(m^{\prime} \omega_{1}+n^{\prime} \omega_{2}\right)
\end{array}\right]}
\end{array}\right\}
\end{aligned}
$$

The corresponding group delay error along $\omega_{1}$ axis is given by

$$
\begin{aligned}
\varepsilon_{g_{1}}\left(\omega_{1}, \omega_{2}\right) \triangleq & W_{g}\left(\omega_{1}, \omega_{2}\right)\left[G D 1\left\{H\left(e^{j \omega_{1}}, e^{j \omega_{2}}\right)\right\}-g_{d_{1}}\right] \\
= & W_{g}\left(\omega_{1}, \omega_{2}\right)\left[\frac{\partial \phi_{1}\left(\omega_{1}, \omega_{2}\right)}{\partial \omega_{1}}+\frac{\partial \phi_{2}\left(\omega_{1}, \omega_{2}\right)}{\partial \omega_{1}}\right. \\
& \left.+\frac{\partial \phi_{3}\left(\omega_{1}, \omega_{2}\right)}{\partial \omega_{1}}+\frac{\partial \phi_{4}\left(\omega_{1}, \omega_{2}\right)}{\partial \omega_{1}}\right]
\end{aligned}
$$

where

$$
\begin{aligned}
\phi_{i}\left(\omega_{1}, \omega_{2}\right) & =\arg \left\{D_{i}\left(e^{j \omega_{1}}, e^{j \omega_{2}}\right)\right\} \\
& =-\tan ^{-1}\left[\frac{\sum_{m} \sum_{n} d_{i}(m, n) \sin \left(m \omega_{1}+n \omega_{2}\right)}{\sum_{m} \sum_{n} d_{i}(m, n) \cos \left(m \omega_{1}+n \omega_{2}\right)}\right] \\
& =-\tan ^{-1}\left[P_{i}\left(\omega_{1}, \omega_{2}\right)\right] .
\end{aligned}
$$

Thus, see (A13), shown at the top of the page. Following the similar procedure, we can also derive the derivatives of group delay error along $\omega_{2}$ axis.

Finally, we derive the derivatives of stability errors for the designs with $\rho=1$ and 2 as follows:

$$
\begin{aligned}
& \text { 1) } \frac{\partial \hat{d}_{s}(m, n)}{\partial d\left(m^{\prime}, n^{\prime}\right)}=F^{-1}\left[\frac{e^{-j\left(m^{\prime} \omega_{1}+n^{\prime} \omega_{2}\right)}}{D\left(e^{j \omega_{1}}, e^{j \omega_{2}}\right)}\right]+F^{-1}\left[\frac{e^{j\left(m^{\prime} \omega_{1}+n^{\prime} \omega_{2}\right)}}{D^{*}\left(e^{j \omega_{1}}, e^{\left.j \omega_{2}\right)}\right.}\right] \\
& \text { 2) } \frac{\partial \hat{D}_{s}(m, n)}{\partial d\left(m^{\prime}, n^{\prime}\right)}=F\left[\frac{\partial \hat{d}_{s}(m, n)}{\partial d\left(m^{\prime}, n^{\prime}\right)}\right] \\
& \text { 3) } \frac{\partial d_{s}(m, n)}{\partial d\left(m^{\prime}, n^{\prime}\right)}=F^{-1}\left[\exp \left(\hat{D}_{s}\left(e^{j \omega_{1}}, e^{j \omega_{2}}\right)\right) \times \frac{\partial \hat{D}_{s}(m, n)}{\partial d\left(m^{\prime}, n^{\prime}\right)}\right] \\
& \text { 4) } \frac{\partial \varepsilon_{s}(m, n)}{\partial d\left(m^{\prime}, n^{\prime}\right)}=\delta\left(m-m^{\prime}, n-n^{\prime}\right)-\frac{\partial d_{s}(m, n)}{\partial d\left(m^{\prime}, n^{\prime}\right)} .
\end{aligned}
$$

\section{ACKNOWLEDGMENT}

The authors would like to thank Dr. W.-S. Lu for the provision of the simulation data used in making comparison for Example 4. The authors would also like to thank to the associate editor and the reviewers for their constructive comments, which have greatly improved the quality of the paper.

\section{REFERENCES}

[1] P. P. Vaidyanathan, S. K. Mitra, and Y. Neuvo, "A new approach to the realization of low sensitivity IIR digital filters," IEEE Trans. Acoust., Speech, Signal Process., vol. ASSP-34, no. 4, pp. 350-361, Apr. 1986.

[2] P. P. Vaidyanathan, P. Regalia, and S. K. Mitra, "Design of doubly complementary IIR digital filters using a single complex allpass filter, with multirate applications," IEEE Trans. Circuits Syst., vol. 34, no. 4, pp. 378-389, Apr. 1987.

[3] M. Ikehara, M. Funaishi, and H. Kuroda, "Design of complex all-pass networks using Remez algorithm," IEEE Trans. Circuits Syst. II, Analog Digit. Signal Process., vol. 39, no. 8, pp. 549-556, Aug. 1992.

[4] S. S. Lawson and A. Klouche-Djedid, "Technique for design of twochannel approximately linear phase QMF bank and its application to image compression," IEE Proc. Vis., Image, Signal Process., vol. 148, no. 2, pp. 85-92, Apr. 2001.

[5] J.-H. Lee and Y.-H. Yang, "Design of two-channel linear-phase QMF banks based on real IIR allpass filters," IEE Proc. Vis., Image, Signal Process., vol. 150, no. 5, pp. 331-338, Oct. 2003.

[6] H. Toyoshima, M. Ikehara, and S. Takahashi, "A new class of 2-D digital filters composed of allpass subfilters," in Proc. Eur. Conf. Circuit Theory and Design, Brighton, U.K., Sep. 5-8, 1989, pp. 420-424.

[7] M. S. Anderson and S. S. Lawson, "Direct design of approximately linear phase (ALP) 2-D digital filters," Electron. Lett., vol. 29, no. 9 , pp. 804-805, Apr. 1993.

[8] H. Safiri, M. Ahmadi, and V. Ramachandran, "Design of stable, causal 2-D digital filters using real coefficient 2-D allpass building blocks," IEEE Trans. Circuits Syst. II, Analog Digit. Signal Process., vol. 44, no. 5, pp. 409-412, May 1997.

[9] A. Lee, M. Ahmadi, and R. S. Lashkari, "Design of stable 2-D recursive filters using power-of-two coefficients," in Proc. IEEE Int. Conf. Electronics, Circuits and Systems, Lisbon, Portugal, Sep. 7-10, 1998 , vol. 2, pp. 409-412. 
[10] M. P. Ekstrom and J. W. Woods, "Two-dimensional spectral factorization with applications in recursive digital filtering," IEEE Trans. Acoust., Speech, Signal Process., vol. ASSP-24, no. 2, pp. 115-128, Apr. 1976.

[11] M. P. Ekstrom, R. E. Twogood, and J. W. Woods, "Two-dimensional recursive filter design - A spectral factorization approach," IEEE Trans. Acoust., Speech, Signal Process., vol. ASSP-28, no. 1, pp. 16-26, Feb. 1980.

[12] J. W. Woods, J.-H. Lee, and I. Paul, "Two-dimensional IIR filter design with magnitude and phase error criteria," IEEE Trans. Acoust., Speech, Signal Process., vol. ASSP-31, no. 4, pp. 886-894, Aug. 1983.

[13] J.-H. Lee and Y.-M. Chen, "A new method for the design of two-dimensional recursive digital filters," IEEE Trans. Acoust., Speech, Signal Process., vol. 36, no. 4, pp. 589-598, Apr. 1988.

[14] J.-H. Lee and Y.-H. Yang, "Minimax design of two-channel nonuniform-division filter banks using IIR allpass filters," IEEE Trans. Signal Process., vol. 52, no. 11, pp. 3227-3240, Nov. 2004.

[15] T. Steihaug, "The conjugate gradient method and trust regions in large scale optimization," SIAM J. Numer. Anal., vol. 20, no. 3, pp. 626-637, Jun. 1983.

[16] J. Nocedal and S. J. Wright, Numerical Optimization. New York: Springer-Verlag, 1999.

[17] P. Embree, J. P. Burg, and M. M. Backus, "Wideband velocity filtering-The pie-slice process," Geophysics, vol. 28, pp. 948-974, 1963.

[18] K. Nishikawa, T. Yamamoto, K. Oto, and T. Kanamori, "Wideband beamforming using fan filter," in Proc. IEEE Int. Symp. Circuits and Systems, San Diego, CA, May 10-13, 1992, vol. 2, pp. 533-536.

[19] T. Sekigushi and Y. Karasawa, "Design of FIR fan filters used for beamspace adaptive array for broadband signals," in Proc. IEEE Int. Symp. Circuits and Systems, Hong Kong, Jun. 9-12, 1997, vol. 4, pp. 2453-2456.

[20] T. Sekigushi and Y. Karasawa, "Wideband beamspace adaptive array utilizing FIR fan filters for multibeam forming," IEEE Trans. Signal Process., vol. 48, no. 1, pp. 277-284, Jan. 2000.

[21] M. Ghavami and R. Kohno, "Recursive fan filters for a broad-band partially adaptive antenna," IEEE Trans. Commun., vol. 48, no. 1, pp. 185-188, Feb. 2000.

[22] M. Ghavami, "Wideband smart antenna theory using rectangular array structures," IEEE Trans. Signal Process., vol. 50, no. 9, pp. 2143-2151, Sep. 2002.

[23] W.-S. Lu and A. Antoniou, "Minimax design of 2-D IIR digital filters using sequential semidefinite programming," in Proc. IEEE Int. Symp. Circuits and Systems, Phoenix, AZ, May 26-29, 2002, vol. 3, pp. III353-III-356.

[24] W.-S. Lu and T. Hinamoto, "Optimal design of IIR digital filters with robust stability using conic-quadratic-programming updates," IEEE Trans. Signal Process., vol. 51, no. 6, pp. 1581-1592, Jun. 2003.
[25] B. Dumitrescu, "Optimization of two-dimensional IIR filters with nonseparable and separable denominator," IEEE Trans. Signal Process., vol. 53, no. 5, pp. 1768-1777, May 2005.

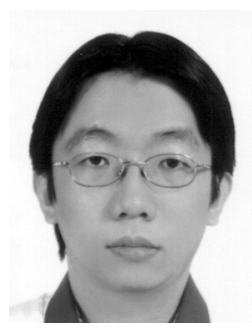

Yuan-Hau Yang was born in Yun-Lin, Taiwan, R.O.C., on March 5, 1977. He received the B.S. degree in communication engineering from the National Chiao-Tung University, Hsin-Chu, Taiwan, in 2000, and the M.S. degree in communication engineering from the National Taiwan University, Taipei, Taiwan, in 2003. He is currently pursuing the $\mathrm{Ph} . \mathrm{D}$. degree in communication engineering at the National Taiwan University, Taipei.

His current research interests include multidimensional digital signal processing and its applications.

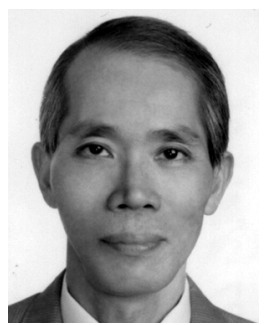

Ju-Hong Lee was born in I-Lan, Taiwan, R.O.C., on December 7, 1952. He received the B.S. degree from the National Cheng-Kung University, Tainan, Taiwan, in 1975, the M.S. degree from the National Taiwan University (NTU), Taipei, in 1977, and the Ph.D. degree from Rensselaer Polytechnic Institute, Troy, NY, in 1984, all in electrical engineering.

From September 1980 to July 1984, he was a Research Assistant and was involved in research on multidimensional recursive digital filtering in the Department of Electrical, Computer, and Systems Engineering, Rensselaer Polytechnic Institute. From August 1984 to July 1986, he was a Visiting Associate Professor and, later in August 1986, he became an Associate Professor in the Department of Electrical Engineering, NTU, where he has been a Professor since August 1989. He was appointed Visiting Professor in the Department of Computer Science and Electrical Engineering, University of Maryland, Baltimore, during a sabbatical leave in 1996. His current research interests include multidimensional digital signal processing, image processing, detection and estimation theory, analysis and processing of joint vibration signals for the diagnosis of cartilage pathology, and adaptive signal processing and its applications in communications.

Dr. Lee received Outstanding Research Awards from the National Science Council (NSC) in the academic years of 1988, 1989, and 1991-1994; Distinguished Research Awards from the NSC in the academic years of 1998-2004; and the NSC Research Fellowship for the academic years 2005-2008. In August 2006, he was appointed NTU's Tenured Distinguished Professor. 